\title{
Analysis of Challenges for Blockchain Adoption within the Indian Public Sector: An Interpretive Structural Modelling Approach
}

\author{
Nripendra P. Rana* \\ School of Management \\ University of Bradford \\ Richmond Road, Bradford BD7 1DP, UK \\ Email: nrananp@gmail.com \\ Yogesh K. Dwivedi \\ School of Management \\ Swansea University Bay Campus \\ Fabian Way, Swansea, SA1 8EN, UK \\ Email: ykdwivedi@gmail.com \\ D. Laurie Hughes \\ School of Management \\ Swansea University Bay Campus \\ Fabian Way, Swansea, SA1 8EN, UK \\ Email: d.1.hughes@ swansea.ac.uk
}

*Corresponding Author 


\title{
Analysis of Challenges for Blockchain Adoption within the Indian Public Sector: An Interpretive Structural Modelling Approach
}

\begin{abstract}
Purpose - Blockchain is one of the most significant emerging technologies that is set to transform many aspects of industry and society. However, it has several major technical, social, legal, environmental and ethical complexities that offer significant challenges for mainstream use within the public sector. The Covid-19 pandemic has compelled many public sector employees to work remotely, highlighting a number of challenges to blockchain adoption within the Indian context signifying the pertinence of this research topic in the post-pandemic era. This study offers insight to researchers and policymakers alike on how such challenges are interdependent within this important subject.

Design/methodology/approach - We explored 16 unique sets of challenges selected from the literature and gathered data from nine experts from government settings, healthcare and education sectors and academia who have significant knowledge and experience of blockchain implementation and use in their respective organisations. The implementation of Interpretive Structural Modelling (ISM) and MICMAC provided a precise set of driving, linkage and dependent challenges that were used to formulate the framework.

Findings - The developed ISM framework is split into six different levels. The results suggest that the bottom level consists of challenges such as 'Lack of standards (C9)' and 'Lack of validation (C10)' form the foundation of the hierarchical structure of blockchain adoption. However, the topmost level consists of a highly dependent challenge termed 'adoption of blockchain in the public sector (C16)'. The research filters the selected set of five challenges to develop a parsimonious model and formulated six propositions to examine the impact of 'lack of standard (C9)', 'lack of validation (C10)' on 'security issues (C3)' and 'privacy concerns (C2)', which eventually determine individuals' 'reluctance to use blockchain technology $(\mathrm{C} 12)$ '.

Originality/Value - This research fills a key gap in exiting research by exploring the key challenges in blockchain adoption within the public sector by developing a valuable framework to model this important topic. To the best of our knowledge, this is the first paper to address these challenges and develop a parsimonious model for challenges of blockchain adoption in the public sector settings.
\end{abstract}

Keywords: Blockchain, Adoption, Challenges, Public Sector, Interpretive Structural Modelling, MICMAC, India

Paper Type Research Paper

\section{Introduction}

Blockchain is a distributed database of records, or public ledger of all transactions or digital events that are accomplished and shared among participating stakeholders (Ali et al., 2020; Crosby et al., 2016). It is considered as one of the most important and relevant technology trends that is likely to significantly impact business and society (Dubey et al., 2020; Olnes et al., 2017). Blockchain has emerged as a potentially disruptive and general purpose technology for organisations seeking to develop information conversation and transactions that require 
authentication and trust (Yli-Huumo et al., 2016). Blockchain technology has the potential to provide significant benefits to various sectors including: healthcare, government and society presenting the next step in electronic government development, offering reduced cost, and promotion of trusted processes and recordkeeping. The technology offers improved the transparency, privacy and security, accuracy and value capture particularly cost savings and value network largely enhancing data accessibility and minimising intermediation within digital processes (Palas and Bunduchi, 2020). However, the technology may result in technical, social, legal, environmental and ethical barriers that make blockchain impractical for mainstream use in the public sector in its present form.

Public sector organisations can receive large savings of time and cost by adopting blockchain technology. These benefits are illustrated in the Estonia case study where an emerging use of the technology led to the savings of $\$ 500$ million per year, equivalent to $2 \%$ of the country's overall GDP (Anthes, 2015). The Estonian government specified that the use of X-Road (a blockchain like middleware) and related acceleration of processes, could save around 800 years of working time per year (Fridgen, 2018; PwC, 2018). Within emerging economies such as India, a number of leading banks including: Standard Chartered, Mumbai ICICI, HDFC, Kotak Mahindra, and Axis bank are amongst a consortium of 11 big lenders to launch the country's first blockchain-linked funding for Small and Medium Enterprises (SMEs) to deliver a number of benefits including: reducing supply-chain financing timeframes, ensuring cost reduction, allow better access to credit and increase the number of SMEs within the formal credit system. It is expected that this new initiative will make lending more transparent and less susceptible to fraud (Economic Times, 2019; Hughes et al. 2019).

A blockchain-based public sector can provide numerous benefits such as secure storage of government, citizen and business data, eliminating redundancy in operational processes and disproportionate costs associated with managing accountability, optimised possibilities for corruption and manipulation, enhanced trust in government and online civil systems, improved efficiency and speed highlighting why so many governments are actively exploring its increasing use globally (Consensys, 2020; Killmeyer et al., 2017). Adopting blockchain technology for rapid, affordable and effective remittances for the international payments, is crucial for India to accomplish its dream to become a $\$ 5$ trillion economy in the next five years. The adoption of blockchain technology to ensure more reasonable and rationalised payments, can alter the landscape of India's economy and expedite country's GDP growth (Palavesh, 2019). 
However, a recent Gartner report has highlighted that in 2021 as much as $90 \%$ of current enterprise blockchain platforms will need to be replaced within 18 months to ensure they remain competitive (Gartner, 2019). A report by Markets and Markets suggests that the blockchain sector size is expected to grow from $\$ 1.2$ billion in 2018 to $\$ 23.3$ billion in 2023 . However, to remain viable in the face of growing competition and security threats, the existing blockchain platforms need to re-invent themselves (Ahaskar, 2019). Therefore, the importance of understanding the potential challenges to blockchain implementation within the public sector and recognise how they would be interrelated to each other, is extremely vital. Most of the academic research in the area of blockchain, generally exhibits a technical focus lacking a methodical discussion on business, management or social implications (Tang et al., 2019). To the best of our knowledge, there is a lack of research that has explored the challenges for blockchain adoption within the public sector particularly the analysis of blockchain hierarchical linkage. This technology is very much needed in the public sector as it offers significant potential to transform many aspects in advancing the public sector. The need for academic research in this area is felt even more considering the fragmented and scattered knowledge on this topic within the public sector context. Therefore, the following research questions are presented:

$\boldsymbol{R Q 1}$. What are the key challenges for the adoption of blockchain in the context of the public sector entities particularly in India and whether they are interlinked with each other?

$\boldsymbol{R Q 2}$. Can these challenges be classified into some major groups based on their specific characteristics?

RQ3. Can a framework be created from the identified challenges that could be used to improve the adoption of blockchain?

In the post-COVID era, when many public sector organisations are rethinking their digital strategy, selecting the optimal use of blockchain has the potential to significantly help move away from siloed and inefficient centralised systems. Moreover, the blockchain network will allow them to offer more secure, agile and cost-efficient structures in comparison to insecure and costly current systems (BDO, 2020). However, there are a range of different challenges to the successful adoption of blockchain within public sector organisations. But there has been limited attempt made to correlate these scattered and unrelated challenges to derive more meaning on how they may be interrelated to each other.

Therefore, this research will aim to recognise the key challenges for blockchain adoption in the public sector and how they could be interlinked to each other. The Interpretive Structural Modelling (ISM) and MICMAC (Matriced' Impacts Croise's Multiplication Appliquée a UN 
Classement) based approaches are used to support the development of a framework for these challenges and interrelationships to prioritise mitigating their impact for improved adoption of blockchain technology within the public sector (Xiao et al., 2020). Emerging from the aim of this study, the following objectives are set for this study:

1. To identify the key challenges and the key interdependencies between the set of challenges relating to blockchain adoption within the public sector,

2. To classify these challenges based on their driving and dependence power and position them in a specific quadrant using a MICMAC diagram,

3. To develop a hierarchical structural model of challenges relating to blockchain adoption in the public sector that establishes the key interrelationships and dependencies with other interconnected blockchain factors.

This study posits a number of theoretical contributions to the ongoing discourse of the blockchain adoption research in the public sector context in general. First, the paper contributes by identifying some key challenges by reviewing the relevant literature and identifying the key challenges. Second, this study establishes the interdependencies between fragmented challenges within and across the hierarchical levels using ISM and MICMAC based approaches. This way the paper provides the methodological contribution by using the novel methods to establish interdependencies between challenges which existed in silos and were largely disjointed before undertaking this research. Finally, the extracted parsimonious research model from the generic ISM based framework provides a unique understanding of some of the key challenges and how they could be considered to be linking through the support of current literature in different contexts to make more sense for understanding them in the perspective of blockchain adoption in the public sector.

The remaining sections of this paper are structured as follows: Section 2 reviews the literature on blockchain to understand the possible challenges of its implementation in the public sector. Section 3 analyses the ISM methodology and its suitability for this research. Section 4 analyses the data collected for the challenges of blockchain implementation in the public sector. Section 5 discusses the findings of this research in the backdrop of available literature on blockchain. Further, Section 6 proposes a parsimonious theoretical model from the generic ISM framework and formulates six propositions between selected variables. Finally, Section 7 concludes the research. 


\section{Literature Review}

We used the combination of keywords: "blockchain" and "public sector" and "blockchain adoption" and "challenges" in both Scopus and Web of Science databases under the title, abstract and keywords. By manually exploring the relevant studies, we found a total of 31 papers that could be investigated matching the key themes of this research. We also used these keywords in Google search engine to find some open source blogs, forums, reviews etc. to see the current ongoing discussion on this topic. However, we have managed to find support for all the key challenges from the academic literature.

The literature has discussed various challenges for blockchain technology for public sector organisations within a number of different contexts (Al-Saqaf and Seidler, 2017; Alketbi et al., 2018; Atlam et al., 2018; Boulos et al., 2018; Crosby et al., 2016; Dorri et al., 2016; Lacity, 2018; Mendling et al., 2018; Reyna et al., 2018; Wang et al., 2017; Zheng et al., 2017, 2018). The research by Al-Saqaf and Seidler (2017) posited the lack of standards and interoperability within the public sector as a key challenge that prevents the widespread adoption of the blockchain technology. Alketbi et al. (2018) argue that although blockchain promises to overcome a number of security challenges including secure data sharing and data integrity, it also presents new security challenges to be further examined and confronted. Atlam et al. (2018) highlighted a number of blockchain adoption challenges including scalability, legal and compliance and lack of adequate skills (Crosby et al., 2016). Boulos et al. (2018) argued that blockchain faces similar challenges as any other technology threatening to disrupt existing processes and mentioned some of its challenges including interoperability, security and privacy as well as the need to explore suitable and sustainable business models of implementation. Dorri et al. (2016) discussed the adoption of blockchain within Internet of Things (IoT) initiatives and highlighted key challenges such as computational overhead and time taken in the mining of blocks, poor scaling of nodes and significant traffic load when the number of nodes in the network increases.

Lacity (2018) described the challenges of blockchain technology in the areas of scalability, performance and interoperability with other systems. In addition, the author also highlighted the management challenges of blockchain applications including standards, regulation, shared governance and building a viable ecosystem that impedes progress. Mendling et al. (2018) described a number of technological challenges that blockchain still faces. These include throughput, latency, size and bandwidth, limited usability, security and wasted resources. Reyna et al. (2018) also discussed a number of challenges of blockchain implementation 
including storage capacity and scalability, security, anonymity and data privacy and legal issues.

Wang et al. (2017) argued that blockchain is still in the early stage of development and faces a number of technical, sector related and human-related challenges. The technical challenges include throughput (i.e. a theoretical current optimal number is seven transactions per second), latency, size and bandwidth in the terms of length of time to download the blockchain). The study highlighted that generally companies are used to maintain their business activities in their own ledger and therefore, conceptually it is difficult for them to change their processes to using a distributed ledger. The enterprise resource planning (ERP) systems have been developed and implemented by many organisations within the last few decades and would incur further significant investment in order to migrate to blockchain based systems. In addition, the human-related challenges such as lack of awareness and understanding of this technology prevents blockchain from further diffusion within organisations. Zheng et al. $(2017,2018)$ argued that blockchain is facing multifaceted challenges and summarised three typical challenges of this technology including scalability, privacy leakage and selfish mining. Selfish mining is an approach for mining bitcoin in which a group of miners conspire to increase their revenue by creating their own private branch of the blockchain.

\subsection{Limitations of existing research}

Although the literature has presented a number of different challenges associated with blockchain initiatives, existing studies seem to omit any substantive analysis of the numerous factors associated with these individual challenges and how they could be associated with each other within a generic framework identifying interdependency. The literature seems largely disjointed with minimal review of diverse studies on blockchain within a business context. Research on blockchain as a source to improve financial exclusion has not considered the relevance of adoption (Schuetz and Venkatesh, 2020). Although studies have studied the opportunities and challenges of blockchain from a government perspective (Swan, 2017) and the topic of designing blockchain based solutions for entrepreneurs (Larios-Hernandez, 2017), none of the existing studies have examined the challenges for the blockchain adoption for the public sector organisations in India. This is a limitation of the emergent literature as adoption is a vital factor that determines how the emerging technology such as blockchain can generate constructive outcomes (Schuetz and Venkatesh, 2020).

Although adoption research of emerging technology is a growing body of research for countries like India (Venkatesh and Sykes, 2013), researchers have not focused on blockchain in the public sector context. For example, researchers such as Kamble et al. (2019, 2020), 
Karamchandani et al. (2020), Queiroz and Wamba (2019), Queiroz et al. (2020), Wamba et al. (2020) and Yadav et al. (2020) examined the adoption of blockchain in India but studied the blockchain adoption in India but they all studied it by Indian professionals in relation to supply chain management perspective. Hughes et al. (2019) have also found that significant challenges of blockchain technology must be overcome before propagation to mainstream adoption. This research aims to fill the identified research gap by performing a structural analysis of the emerging key challenges for the adoption of the blockchain technology in the public sector organisations and their interrelationships using ISM-MICMAC approach.

\subsection{Challenges to blockchain adoption within the public sector}

Based on the review of literature, this study has identified 16 challenges of blockchain adoption. These challenges were further authenticated from the experts by asking them to rate the relevance of these challenges on a Likert scale of [1-5] with ' 1 ' represents 'not significant' and ' 5 ' specifies 'extremely significant' options. Table I presents these challenges with their implicit meaning and the studies where they are referenced.

Table I.

Blockchain adoption challenges in the public sector

\begin{tabular}{|c|c|c|c|}
\hline SN & Challenge & Implied Meaning & Source(s) \\
\hline 1 & Scalability (C1) & $\begin{array}{l}\text { The blocks in the blockchain continue to } \\
\text { grow with use and each transaction needs } \\
\text { more time to be processed. The blockchain } \\
\text { scalability problem related to the fact that } \\
\text { records (or blocks) in the blockchain are } \\
\text { limited in size and frequency }\end{array}$ & $\begin{array}{l}\text { Atlam et al. (2018), Biswas } \\
\text { and Gupta (2019), Lacity } \\
\text { (2018), Zheng et al. (2017, } \\
\text { 2018) }\end{array}$ \\
\hline 2 & Privacy $(\mathrm{C} 2)$ & $\begin{array}{l}\text { Given that blockchain transactions are } \\
\text { posted on the public database for review by } \\
\text { anyone, creates an environment that leads } \\
\text { to privacy issues for this technology }\end{array}$ & $\begin{array}{l}\text { Biswas and Gupta (2019), } \\
\text { Zheng et al. }(2017,2018)\end{array}$ \\
\hline 3 & Security (C3) & $\begin{array}{l}\text { Issues related to security (e.g. endpoint } \\
\text { vulnerabilities, vendor risks, untested at full } \\
\text { scales, untested code etc.) can inversely } \\
\text { affect the implementation of blockchain in } \\
\text { the public sector }\end{array}$ & $\begin{array}{l}\text { Alketbi et al. }(2018) \text {, } \\
\text { Mendling et al. } \\
\text { Thakur et al. (2018), }\end{array}$ \\
\hline 4 & $\begin{array}{l}\text { Regulatory compliance } \\
\text { (C4) }\end{array}$ & $\begin{array}{l}\text { Lack of regulatory compliance impacts the } \\
\text { successful implementation and use of } \\
\text { blockchain in the public sector }\end{array}$ & $\begin{array}{l}\text { Atlam et al. (2018), Biswas } \\
\text { and Gupta (2019), Crosby et } \\
\text { al. (2016) }\end{array}$ \\
\hline 5 & $\begin{array}{l}\text { Lack of adequate skills } \\
\text { (C5) }\end{array}$ & $\begin{array}{l}\text { Lack of adequate skills among the } \\
\text { executives and employees to handle } \\
\text { blockchain technology would affect the } \\
\text { way blockchain has been planned to be } \\
\text { implemented and use in the public sector }\end{array}$ & Atlam et al. (2018) \\
\hline 6 & Initial cost (C6) & $\begin{array}{l}\text { Cost to install, maintain and secure } \\
\text { blockchain has a negative impact on the } \\
\text { implementation and use of this technology } \\
\text { in the public sector }\end{array}$ & $\begin{array}{l}\text { Bailis et al. (2017), Gomber } \\
\text { et al. (2018) }\end{array}$ \\
\hline 7 & $\begin{array}{l}\text { Integration with legacy } \\
\text { system (C7) }\end{array}$ & $\begin{array}{l}\text { Integration of blockchain with the existing } \\
\text { legacy systems of the public sector impedes } \\
\text { it from implementing and being used in the } \\
\text { public sector }\end{array}$ & Hughes et al. (2019) \\
\hline
\end{tabular}




\begin{tabular}{|c|c|c|c|}
\hline 8 & Legal issues (C8) & $\begin{array}{l}\text { Legal issues (e.g. smart contracts, data } \\
\text { protection regulations, litigation and } \\
\text { dispute resolution) can negatively influence } \\
\text { the implementation and use of blockchain } \\
\text { in the public sector }\end{array}$ & $\begin{array}{l}\text { Atlam et al. (2018), Biswas } \\
\text { and Gupta (2019) }\end{array}$ \\
\hline 9 & Lack of standards (C9) & $\begin{array}{l}\text { Lack of unified standards (e.g. terminology } \\
\text { and concepts, security risks and } \\
\text { vulnerabilities, overview of identity, } \\
\text { reference architecture, taxonomy and } \\
\text { ontology, legally binding smart contracts } \\
\text { etc.) impedes blockchain technology to be } \\
\text { properly implemented and used in the } \\
\text { public sector }\end{array}$ & Al-Saqaf and Seidler (2017) \\
\hline 10 & Lack of validation (C10) & $\begin{array}{l}\text { As the blockchain technology has not been } \\
\text { tested enough in pilots, lack of validation } \\
\text { can hamper its implementation and use in } \\
\text { the public sector }\end{array}$ & $\begin{array}{l}\text { Tang et al. (2019), Tasca and } \\
\text { Tessone (2017) }\end{array}$ \\
\hline 11 & $\begin{array}{l}\text { Lack of understanding } \\
\text { and knowledge (C11) }\end{array}$ & $\begin{array}{l}\text { Lack of mass understanding and knowledge } \\
\text { about blockchain holds this technology } \\
\text { back from being implemented and used by } \\
\text { the public sector }\end{array}$ & $\begin{array}{l}\text { Önder and Treiblmaier } \\
(2018) \text {, White (2017) }\end{array}$ \\
\hline 12 & $\begin{array}{l}\text { Reluctance to use } \\
\text { blockchain technology } \\
\text { (C12) }\end{array}$ & $\begin{array}{l}\text { Reluctance to use the blockchain due to } \\
\text { leading edge technology by individuals will } \\
\text { prevent them from implementing and using } \\
\text { blockchain in the public sector }\end{array}$ & Wang et al. (2019) \\
\hline 13 & Ethical issues (C13) & $\begin{array}{l}\text { Ethical issues (e.g. its effect on the } \\
\text { environment, its apparent enabling of } \\
\text { criminal activity etc.) may have adverse } \\
\text { effect on the implementation and use of } \\
\text { blockchain technology in the public sector }\end{array}$ & $\begin{array}{l}\text { Dierksmeier and Seele } \\
\text { (2018), Tang et al. (2019) }\end{array}$ \\
\hline 14 & Latency cost (C14) & $\begin{array}{l}\text { Due to the integral nature of the architecture } \\
\text { where all blocks in the chain would need to } \\
\text { be synchronised for any new additions. This } \\
\text { could be computationally expensive } \\
\text { especially for large blockchains and a } \\
\text { potential barrier to implementation }\end{array}$ & $\begin{array}{ll}\text { Axios } & (2018), \\
(2017) & \text { Drescher }\end{array}$ \\
\hline 15 & Flexibility (C15) & $\begin{array}{l}\text { Immutable nature of blockchain means that } \\
\text { additional transactions are append only. } \\
\text { This is a benefit on the security side but a } \\
\text { potential challenge for some stakeholders } \\
\text { wishing to modify records }\end{array}$ & 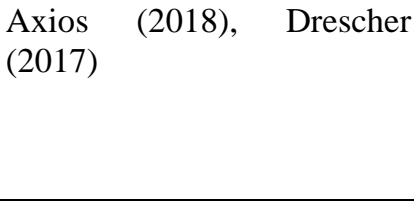 \\
\hline 16 & $\begin{array}{l}\text { Adoption of blockchain } \\
\text { in the public sector (C16) }\end{array}$ & $\begin{array}{l}\text { Decision to adopt or not to adopt } \\
\text { blockchain technology in the public sector }\end{array}$ & Hughes et al. (2019) \\
\hline
\end{tabular}

\section{Research Method}

This study employs the ISM and MICMAC methods to offer a realistic and context-rich approach to build theory and contribution to literature. Warfield (established ISM as an interactive learning tool using expert judgment (Warfield, 1974) to model a group of related variables (directly or indirectly) with the phenomenon. ISM provides a hierarchical structure of variables to depict the type and contextual interrelationships (Mathiyazhagan et al., 2013). The MICMAC evaluates variables based on their driving and dependence power. The ISMMICMAC combination has been widely used within the wider literature (Haleem et al., 2016; Agi and Nishant, 2017). The ISM-MICMAC based approach was selected after a systematic 
review of alternative methodologies such as analytic network process (ANP), DEMATEL, structural equation modeling (SEM), graph theory, analytical hierarchy process (AHP), best worst method (BWM) and total interpretive structural modeling (TISM) (Wagner and Neshat, 2010; Dou et al., 2014; Jakhar and Barua, 2014; Luthra et al., 2017; Mangla et al., 2018; Mathivathanan et al., 2021; Mi et al., 2019; Shibin et al., 2017) (see Table II).

Table II.

Comparison of ISM with other multi criteria decision making methods (Adapted from Mangla et al., 2018)

\begin{tabular}{|c|c|c|c|}
\hline ISM-MICMAC & DEMATEL & ANP & SEM \\
\hline $\begin{array}{l}\text { ISM-MICMAC method } \\
\text { uncovers the contextual } \\
\text { interactions among } \\
\text { variables based on their } \\
\text { driving power potential } \\
\text { and dependencies }\end{array}$ & $\begin{array}{l}\text { DEMATEL helps to } \\
\text { uncovers the causal } \\
\text { interactions among the } \\
\text { variables based on their } \\
\text { cause and effect groups }\end{array}$ & $\begin{array}{l}\text { ANP can provide } \\
\text { interdependencies between } \\
\text { and among the variables; } \\
\text { this method is less accepted } \\
\text { due to its complexity. }\end{array}$ & $\begin{array}{l}\text { SEM is an "a priori" } \\
\text { method, mainly used for } \\
\text { theoretical development } \\
\text { of the model. However, } \\
\text { SEM requires a large } \\
\text { sample size }\end{array}$ \\
\hline Graph Theory & AHP & BWM & TISM \\
\hline $\begin{array}{l}\text { Graph theory is used to } \\
\text { reveal the interlinks } \\
\text { between the variables, } \\
\text { however, the reliability } \\
\text { of the direction of the } \\
\text { edges in the graph is } \\
\text { debatable }\end{array}$ & $\begin{array}{l}\text { AHP does not provide } \\
\text { any interdependencies } \\
\text { between variables, it } \\
\text { however uses to draw } \\
\text { the classified structure of } \\
\text { the variables }\end{array}$ & $\begin{array}{l}\text { BWM can be used to } \\
\text { evaluate the alternatives } \\
\text { with respect to the criteria } \\
\text { particularly in the cases } \\
\text { where objective metrics are } \\
\text { not available to evaluate } \\
\text { the alternatives }\end{array}$ & $\begin{array}{l}\text { TISM is used for theory } \\
\text { building as it helps to } \\
\text { answer the basic research } \\
\text { questions of what, how } \\
\text { and why and helps } \\
\text { identify variables, } \\
\text { relationships and the } \\
\text { reason for causality }\end{array}$ \\
\hline
\end{tabular}

The advantage of DEMATEL is that it can shape the structure of a relation map and consider the interlinks between the identified factors. Besides considering the direct as well as indirect relationship between factors, it also envisages the structure of relations with direct relation matrices (Song et al., 2020). However, it determines the ranking of alternatives based on symbiotic relationships but other criteria are not included in decision making problem and also relative weights of experts are not taken into account while aggregating individual adjudications into group evaluations. Likewise, although the AHP can be used to rank alternatives and determine criteria weights, it considers that the criteria are autonomous and fails to contemplate their connections and dependences. The ANP - an advanced version of AHP, can work with dependence and feedback between criteria but the consideration of equal weight for each cluster to get weighted super matrix is not justifiable in the real-world situation (Sheng-Li et al., 2018).

The advantage of SEM is its capacity to assess and validate the relationships between constructs, however it allows for the use of multiple items to represent those constructs. Moreover, in SEM, the researchers must determine various test statistics and fit indices to ensure that the model perfectly represents the relationships between constructs and observed variables (Weston and Gore Jr, 2006). BWM is an multi criteria decision making (MCDM) method where the decision maker selects the best and the worst criteria and two pairwise 
comparison vectors hence this method would need fewer comparisons (Sadjadi and Karimi, 2018). The disadvantage of this method is the complex computations and failing to meet stop conditions (Mahmoudi et al., 2020). Finally, graph theory is a multi-criteria decision-making approach used to establish interlinks between variables however the reliability of the direction for the edges in the graph is still arguable (Mangla et al., 2018).

We employed ISM-MICMAC based methodology as this technique has several advantages: [i] this process is systemic, as the process considers all potential pairwise correlations of systems elements either through participants' response or transitive extrapolation, [ii] The process is efficient as the use of transitive interpretation may decrease the relational queries by $50-80 \%$, [iii] It guides and records the results of group discussions on complicated issues in an effective and methodical manner, [iv] It improves the quality of interdisciplinary and interpersonal communication by bringing the attention of participants to the one particular question at a time, [v] it serves as a learning tool for deeper understanding of the meaning and significance for the specified list of challenges and revealing their contextual relationships for the adoption of blockchain technology as well as well-accepted method in the existing literature (Attri et al., 2013; Rana et al., 2019, 2020).

Moreover, the ISM-MICMAC approach does have some inherent weaknesses. These include [i] Increase in the number of variables for a given issue enhances the complexity of this methodology, [ii] The models developed using ISM-MICMAC are not empirically validated, and [iii] Only experts in the given field could be considered as the potential respondents for data collection (Attri et al., 2013). We were able to overcome all the limitations of the ISMMICMAC based research as we only used experts to collect data for the challenges identified for the blockchain technology, the modest number of challenges emerged through literature and the purpose of the framework developed through ISM-MICMAC approach was to develop the framework using interrelationships of challenges but not to empirically validate them using this research only.

A variant of the ISM based approach is total interpretive structural modelling (TISM). Whereas ISM interprets only the nodes, TISM interprets both nodes and links in the diagraph. Moreover, TISM incorporates some important transitive links to provide better explanatory framework whereas ISM eliminates all of them. TISM is a method that endeavors to answer three basic questions of theory development: "what" is answered by presenting nodes as variables whereas "why" and "how" demonstrate the interlinks (Sushil, 2018; Dubey et al., 2017). However, with the increasing number of variables, demonstrating the diagraph with transitive links may be more confusing to understand their interlinks. Therefore ISM could be a more suitable 
methodology for such contexts. Consequentially, ISM was selected instead of TISM as a proposed methodology for this research.

According to Raut et al. (2017) the ISM-MICMAC process (see Figure 1) entails: [i] Identifying the variables that are linked to the research problem (e.g. 16 key challenges of blockchain adoption in the public sector of India) from a literature survey and expert feedback, [ii] Developing contextual relationships between challenges through data collection and creating a structural self-interaction matrix (SSIM) of identified challenges using pair-wise comparisons and experts' input, [iii] Creating an initial "reachability matrix" (IRM) using SSIM and refining it to create a final reachability matrix (FRM) using transitivity relations amongst challenges (Agarwal et al., 2007; Rana et al., 2019, 2020; Saxena and Vrat, 1990), [iv] Computing the driving power and dependencies of each challenge by summing the values (rows and columns of FRM) then generating an FRM hierarchy using reachability and antecedent sets.

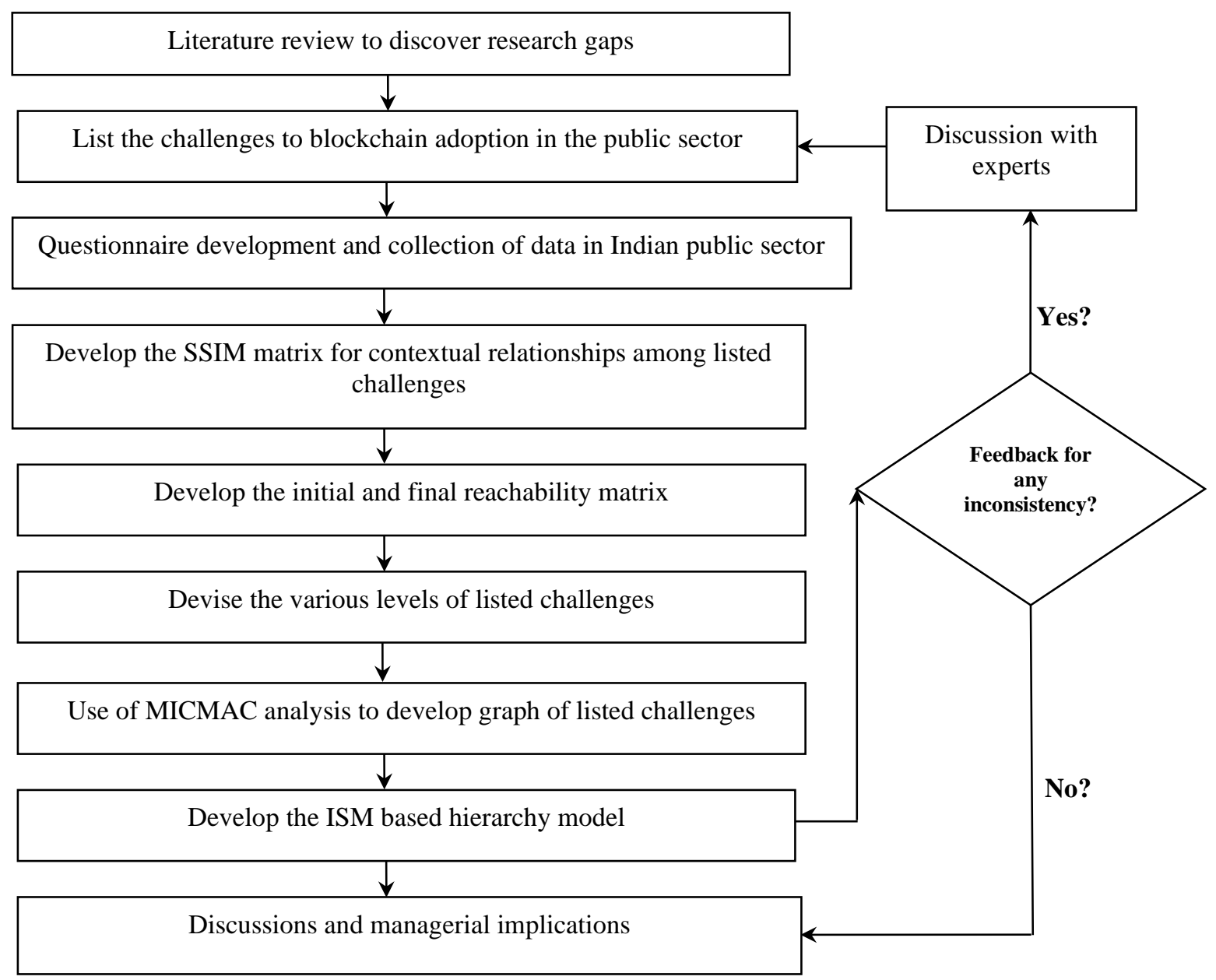

Figure 1. ISM-MICMAC based flowchart 
A reachability set is composed of the challenge and those challenges influenced by it. Antecedent sets include the challenge and other challenges that influence the main challenge. After combination of sets and intersection set is derived, [v] The next stage is to use the MICMAC method to create a graph of listed challenges using the computed driving powers and challenge dependencies. Four distinct regions are then used (autonomous, dependent, linkage, and drivers) to ground expert inputs (Sindhwani and Malhotra, 2017), and [vi] A digraph of listed challenges (FRM) is then created to visualize challenge relationships and the final stage is to develop an ISM-based structural model using the reachability and intersection data sets to enable the analysis of the outcome ISM model for consistency (through expert input) and consistency to allow recommendations of suitable actions to be recommended to government officials and practicing improvement facilitators (Dubey and Ali, 2014). The ISMMICMAC based flow chart of this research is provided in Figure 1.

\section{Data collection and analysis}

Data was collected from experts involved in the Indian public sector, who fulfilled the specific criteria. This exercise probed problematic as there exists a limited pool of experts with this level of in-depth knowledge especially available individuals with actual experience of the blockchain technology implementation. Our criteria retained the prerequisite that experts should have a good knowledge of blockchain technology and should have had experience of implementing it in government or public sector projects, and demonstrating impartiality so as they are not engaged by a software vendor or favouring a particular solution.

The panel of experts were sourced from a senior official at the national informatic centre in India. These experts were involved in blockchain implementation projects and also from an academic institution whose staff were involved with blockchain implementation projects. Data was collected from nine experts. These experts have worked on a previous blockchain projects within the state government in Bihar in India together with employees of the national informatics centre who implemented blockchain related projects in the government healthcare and education sectors within the state. The analysis of the data was performed using the ISMMICMAC approach. The stepwise details of the functioning of the approach are provided in Section 4.3 onward.

\subsection{Questionnaire development and data collection}

The data collection instrument was developed on the challenges of blockchain adoption within the public sector. The questionnaire was developed in three key sections. The first section consists of questions relating to respondents' personal details and questions related to their 
organisation and sector in which they work. The second section asks respondents the questions relating to significance of challenges of adoption of blockchain in the public sector organisations. The respondents were provided with the five-point Likert scale starting with ' 1 ' indicating 'not significant' to ' 5 ' as 'extremely significant' option. Respondents were asked to provide the most appropriate options for each challenge for the blockchain adoption. The third section provides a table of challenges where contextual relationships between each pair of challenges are mentioned using one of the four characters i.e. ' $\mathrm{V}$ ', ' $\mathrm{A}$ ', ' $\mathrm{X}$ ' and ' $\mathrm{O}$ ' whose meaning is presented below (see questionnaire in Appendix A).

The questionnaire relates to challenges of blockchain adoption and was developed using the selected unique set of factors from the existing literature. The sample size of experts providing data is within the prescribed limit of the ISM methodology and the experts were also experienced enough to have the overall understanding of the factors and their interrelationships. Table III presents the respondents' demographic summary in terms of their job title, education, years of industry experience, organisation size and sector classification.

Table III.

Demographic information on experts

\begin{tabular}{|l|l|c|}
\hline Demographic classification & Category & \# of Experts \\
\hline \multirow{4}{*}{ Job Title } & Academic Member of Staff & 3 \\
\cline { 2 - 3 } & National Informatics Centre (NIC) & 2 \\
\cline { 2 - 3 } & Education Sector & 2 \\
\cline { 2 - 3 } Years of industry experience & Healthcare Sector & 2 \\
\hline \multirow{4}{*}{ Organisational size } & $5-10$ years & 3 \\
\cline { 2 - 3 } & $10-15$ years & 1 \\
\cline { 2 - 3 } & $15-20$ years & 5 \\
\hline \multirow{3}{*}{ Sector type } & More than 50 and less than 250 employees & 3 \\
\cline { 2 - 3 } & More than 250 and less than 500 employees & 1 \\
\cline { 2 - 3 } & More than 500 and less than 1,000 employees & 2 \\
\hline
\end{tabular}

\subsection{Selection of the challenges relevant to blockchain adoption in the public sector}

The initial literature review identified 16 challenges to blockchain adoption in the public sector and the questionnaire (see Table I in Section 2.2) was used to confirm these challenges to exhibit validity within the Indian public sector. An expert panel brainstorming session was conducted and the challenges to blockchain adoption in the public sector (from the literature and ' 5 ' point Likert scale questionnaire) were reviewed. The subsequent discussion and outcome from the expert panel identified challenges scoring a rating of ' 3 ' or greater would be retained. Each of the experts agreed and supported the inclusion of the 16 literature-based challenges to blockchain adoption in the context of Indian public sector. 


\subsection{Development of SSIM, IRM and FRM}

The set of challenges was reviewed using pairwise comparisons to detect the contextual relationships (direction) between challenges was conducted. The questionnaire data was used by the expert panel to determine the contextual relationship between each of the challenges. Each expert was asked to rate each challenge to ascertain the extent of relationship to other connected challenges. Established symbols were used to code the relationships: [i] V - when Challenge $\mathrm{i}$ will lead to Challenge $\mathrm{j}$; [ii] A - when Challenge $\mathrm{j}$ will facilitate/lead to Challenge $\mathrm{i}$; [iii] $\mathrm{X}$ - when challenges $\mathrm{i}$ and $\mathrm{j}$ will facilitate each other; and [iv] $\mathrm{O}$ - when challenges $\mathrm{i}$ and $\mathrm{j}$ are unrelated to each other. The SSIM results are shown in Table IV where each of the experts views on interdependency is illustrated using the prescribed notation.

Table IV.

SSIM for the key challenges of blockchain adoption in the public sector

\begin{tabular}{|c|c|c|c|c|c|c|c|c|c|c|c|c|c|c|c|}
\hline Challenge & C16 & C15 & C14 & C13 & C12 & C11 & C10 & C9 & $\mathrm{C} 8$ & $\mathrm{C} 7$ & C6 & C5 & $\mathrm{C} 4$ & $\mathrm{C} 3$ & $\mathrm{C} 2$ \\
\hline $\mathrm{C} 1$ & $\mathrm{~V}$ & $\mathrm{~V}$ & $\mathrm{O}$ & $\mathrm{V}$ & $\mathrm{V}$ & $\mathrm{V}$ & $\mathrm{A}$ & A & $\mathrm{V}$ & $\mathrm{V}$ & $X$ & $\mathrm{~V}$ & $\mathrm{~V}$ & $\mathrm{~V}$ & $X$ \\
\hline $\mathrm{C} 2$ & $\mathrm{~V}$ & $\mathrm{~V}$ & $\mathrm{~V}$ & $\mathrm{~V}$ & $\mathrm{~V}$ & $\mathrm{~V}$ & $\mathrm{~A}$ & $\mathrm{~A}$ & $\mathrm{~V}$ & $\mathrm{~V}$ & $X$ & $\mathrm{~V}$ & $\mathrm{~V}$ & $\mathrm{X}$ & \\
\hline $\mathrm{C} 3$ & $\mathrm{~V}$ & $\mathrm{~V}$ & $\mathrm{~V}$ & $\mathrm{~V}$ & $\mathrm{~V}$ & $\mathrm{~V}$ & $\mathrm{~A}$ & A & $\mathrm{V}$ & $\mathrm{V}$ & $\mathrm{X}$ & $\mathrm{V}$ & $\mathrm{V}$ & & \\
\hline $\mathrm{C} 4$ & $\mathrm{~V}$ & $\mathrm{~V}$ & $\mathrm{~A}$ & $\mathrm{~V}$ & $\mathrm{~V}$ & $\mathrm{~V}$ & $\mathrm{~A}$ & A & $\mathrm{X}$ & $\mathrm{V}$ & A & $\mathrm{V}$ & & & \\
\hline $\mathrm{C} 5$ & $\mathrm{~V}$ & $\mathrm{X}$ & $\mathrm{A}$ & $\mathrm{A}$ & $\mathrm{V}$ & $\mathrm{X}$ & $\mathrm{A}$ & $\mathrm{A}$ & $\mathrm{A}$ & $\mathrm{V}$ & $\mathrm{A}$ & & & & \\
\hline C6 & $\mathrm{V}$ & $\mathrm{V}$ & $\mathrm{X}$ & $\mathrm{V}$ & $\mathrm{V}$ & $\mathrm{V}$ & A & A & $\mathrm{V}$ & $\mathrm{V}$ & & & & & \\
\hline $\mathrm{C} 7$ & $\mathrm{~V}$ & $\mathrm{~A}$ & $\mathrm{~A}$ & $\mathrm{~A}$ & $\mathrm{X}$ & $\mathrm{A}$ & $\mathrm{A}$ & A & $\mathrm{A}$ & & & & & & \\
\hline $\mathrm{C} 8$ & $\mathrm{~V}$ & $\mathrm{~V}$ & A & $\mathrm{X}$ & $\mathrm{V}$ & $\mathrm{V}$ & A & A & & & & & & & \\
\hline C9 & $\mathrm{V}$ & $\mathrm{V}$ & $\mathrm{V}$ & $\mathrm{V}$ & $\mathrm{V}$ & $\mathrm{V}$ & $\mathrm{X}$ & & & & & & & & \\
\hline $\mathrm{C} 10$ & $\mathrm{~V}$ & $\mathrm{~V}$ & $\mathrm{~V}$ & $\mathrm{~V}$ & $\mathrm{~V}$ & $\mathrm{~V}$ & & & & & & & & & \\
\hline $\mathrm{C} 11$ & $\mathrm{~V}$ & $\mathrm{O}$ & $\mathrm{A}$ & A & $\mathrm{V}$ & & & & & & & & & & \\
\hline $\mathrm{C} 12$ & $\mathrm{~V}$ & A & A & A & & & & & & & & & & & \\
\hline $\mathrm{C} 13$ & $\mathrm{~V}$ & $\mathrm{~V}$ & A & & & & & & & & & & & & \\
\hline $\mathrm{C} 14$ & $\mathrm{~V}$ & $\mathrm{~V}$ & & & & & & & & & & & & & \\
\hline C15 & $\mathrm{V}$ & & & & & & & & & & & & & & \\
\hline
\end{tabular}

The SSIM is then transformed into the Initial Reachability Matrix (IRM) using binary coding (0 and 1) to replace V, A, X, O of the SSIM (see Table V). The basis of this replacement is provided as: [i] Use ' 1 ' in ( $i, j)$ entry and ' 0 ' in $(j, i)$ entry when there is ' $V$ ' in SSIM, [ii] Use ' 0 ' in ( $(i, j)$ entry and ' 1 ' in $(j, i)$ entry when there is ' $A$ ' in SSIM, [iii] Use ' 1 ' in both $(i, j)$ and $(j, i)$ entries when there is ' $X$ ' in SSIM, and [iv] Use ' 0 ' in both ( $i, j)$ and $(j, i)$ entries when there is ' $\mathrm{O}$ ' in SSIM.

Table V.

IRM for the key challenges of blockchain adoption in the public sector

\begin{tabular}{|c|c|c|c|c|c|c|c|c|c|c|c|c|c|c|c|c|}
\hline Challenge & C1 & C2 & C3 & C4 & C5 & C6 & C7 & C8 & C9 & C10 & C11 & C12 & C13 & C14 & C15 & C16 \\
\hline C1 & 1 & 1 & 1 & 1 & 1 & 1 & 1 & 1 & 0 & 0 & 1 & 1 & 1 & 0 & 1 & 1 \\
\hline C2 & 1 & 1 & 1 & 1 & 1 & 1 & 1 & 1 & 0 & 0 & 1 & 1 & 1 & 1 & 1 & 1 \\
\hline C3 & 0 & 1 & 1 & 1 & 1 & 1 & 1 & 1 & 0 & 0 & 1 & 1 & 1 & 1 & 1 & 1 \\
\hline C4 & 0 & 0 & 0 & 1 & 1 & 0 & 1 & 1 & 0 & 0 & 1 & 1 & 1 & 0 & 1 & 1 \\
\hline C5 & 0 & 0 & 0 & 0 & 1 & 0 & 1 & 0 & 0 & 0 & 1 & 1 & 0 & 0 & 1 & 1 \\
\hline C6 & 1 & 1 & 1 & 1 & 1 & 1 & 1 & 1 & 0 & 0 & 1 & 1 & 1 & 1 & 1 & 1 \\
\hline C7 & 0 & 0 & 0 & 0 & 0 & 0 & 1 & 0 & 0 & 0 & 0 & 1 & 0 & 0 & 0 & 1 \\
\hline C8 & 0 & 0 & 0 & 1 & 1 & 0 & 1 & 1 & 0 & 0 & 1 & 1 & 1 & 0 & 1 & 1 \\
\hline C9 & 1 & 1 & 1 & 1 & 1 & 1 & 1 & 1 & 1 & 1 & 1 & 1 & 1 & 1 & 1 & 1 \\
\hline C10 & 1 & 1 & 1 & 1 & 1 & 1 & 1 & 1 & 1 & 1 & 1 & 1 & 1 & 1 & 1 & 1 \\
\hline
\end{tabular}




\begin{tabular}{|c|c|c|c|c|c|c|c|c|c|c|c|c|c|c|c|c|}
\hline $\mathrm{C} 11$ & 0 & 0 & 0 & 0 & 1 & 0 & 1 & 0 & 0 & 0 & 1 & 1 & 0 & 0 & 0 & 1 \\
\hline $\mathrm{C} 12$ & 0 & 0 & 0 & 0 & 0 & 0 & 1 & 0 & 0 & 0 & 0 & 1 & 0 & 0 & 0 & 1 \\
\hline $\mathrm{C} 13$ & 0 & 0 & 0 & 0 & 1 & 0 & 1 & 1 & 0 & 0 & 1 & 1 & 1 & 0 & 1 & 1 \\
\hline $\mathrm{C} 14$ & 0 & 0 & 0 & 1 & 1 & 1 & 1 & 1 & 0 & 0 & 1 & 1 & 1 & 1 & 1 & 1 \\
\hline $\mathrm{C} 15$ & 0 & 0 & 0 & 0 & 1 & 0 & 1 & 0 & 0 & 0 & 0 & 1 & 0 & 0 & 1 & 1 \\
\hline $\mathrm{C} 16$ & 0 & 0 & 0 & 0 & 0 & 0 & 0 & 0 & 0 & 0 & 0 & 0 & 0 & 0 & 0 & 1 \\
\hline
\end{tabular}

The transformation to FRM from the IRM entails the application of transitivity. The results are shown in Table VI. Transitivity is denoted by the following: If $A$ is connected to $B(A \rightarrow B)$ and $B$ is connected to $C(B \rightarrow C)$ then a transitive relationship exists between $A$ and $C(A \rightarrow C)$. Transitive relationships are denoted within the FRM by highlighting " 1 *" at each of the transitive relationship instances. The driving and the dependence power of each challenge are then computed and a summation of the $(i, j)$ entries within the FRM are calculated.

Table VI.

FRM for the key challenges of blockchain adoption

\begin{tabular}{|c|c|c|c|c|c|c|c|c|c|c|c|c|c|c|c|c|c|}
\hline Challenge & C1 & C2 & C3 & C4 & C5 & C6 & C7 & C8 & C9 & C10 & C11 & C12 & C13 & C14 & C15 & C16 & $\begin{array}{l}\text { Driving } \\
\text { Power }\end{array}$ \\
\hline C1 & 1 & 1 & 1 & 1 & 1 & 1 & 1 & 1 & 0 & 0 & 1 & 1 & 1 & $1^{*}$ & 1 & 1 & 14 \\
\hline C2 & 1 & 1 & 1 & 1 & 1 & 1 & 1 & 1 & 0 & 0 & 1 & 1 & 1 & 1 & 1 & 1 & 14 \\
\hline C3 & $1^{*}$ & 1 & 1 & 1 & 1 & 1 & 1 & 1 & 0 & 0 & 1 & 1 & 1 & 1 & 1 & 1 & 14 \\
\hline C4 & 0 & 0 & 0 & 1 & 1 & 0 & 1 & 1 & 0 & 0 & 1 & 1 & 1 & 0 & 1 & 1 & 09 \\
\hline C5 & 0 & 0 & 0 & 0 & 1 & 0 & 1 & 0 & 0 & 0 & 1 & 1 & 0 & 0 & 1 & 1 & 06 \\
\hline C6 & 1 & 1 & 1 & 1 & 1 & 1 & 1 & 1 & 0 & 0 & 1 & 1 & 1 & 1 & 1 & 1 & 14 \\
\hline C7 & 0 & 0 & 0 & 0 & 0 & 0 & 1 & 0 & 0 & 0 & 0 & 1 & 0 & 0 & 0 & 1 & 03 \\
\hline C8 & 0 & 0 & 0 & 1 & 1 & 0 & 1 & 1 & 0 & 0 & 1 & 1 & 1 & 0 & 1 & 1 & 09 \\
\hline C9 & 1 & 1 & 1 & 1 & 1 & 1 & 1 & 1 & 1 & 1 & 1 & 1 & 1 & 1 & 1 & 1 & 16 \\
\hline C10 & 1 & 1 & 1 & 1 & 1 & 1 & 1 & 1 & 1 & 1 & 1 & 1 & 1 & 1 & 1 & 1 & 16 \\
\hline C11 & 0 & 0 & 0 & 0 & 1 & 0 & 1 & 0 & 0 & 0 & 1 & 1 & 0 & 0 & $1 *$ & 1 & 06 \\
\hline C12 & 0 & 0 & 0 & 0 & 0 & 0 & 1 & 0 & 0 & 0 & 0 & 1 & 0 & 0 & 0 & 1 & 03 \\
\hline C13 & 0 & 0 & 0 & $1 *$ & 1 & 0 & 1 & 1 & 0 & 0 & 1 & 1 & 1 & 0 & 1 & 1 & 09 \\
\hline C14 & $1^{*}$ & $1^{*}$ & $1^{*}$ & 1 & 1 & 1 & 1 & 1 & 0 & 0 & 1 & 1 & 1 & 1 & 1 & 1 & 14 \\
\hline C15 & 0 & 0 & 0 & 0 & 1 & 0 & 1 & 0 & 0 & 0 & $1 *$ & 1 & 0 & 0 & 1 & 1 & 06 \\
\hline C16 & 0 & 0 & 0 & 0 & 0 & 0 & 0 & 0 & 0 & 0 & 0 & 0 & 0 & 0 & 0 & 1 & 01 \\
\hline $\begin{array}{c}\text { Dependence } \\
\text { Power }\end{array}$ & 07 & 07 & 07 & 10 & 13 & 07 & 15 & 10 & 02 & 02 & 13 & 15 & 10 & 07 & 13 & 16 & 154 \\
\hline
\end{tabular}

\subsection{Level partitioning}

The matrices are next decomposed into levels of importance to create a 'causal' hierarchical structure. This is achieved with the use of reachability, antecedent and intersection sets. Reachability involves the processing of each challenge and the other identified challenges that could be influenced, whereas the antecedent is composed of the challenge and all other challenges that may affect it. The combination of reachability and antecedent sets reveals an intersection set and this procedure is repeated for all challenges. Level 1 status was recorded where the reachability and intersection sets are equal for any challenge (e.g. 'Adoption of blockchain in the public sector (C16)'). After recording a challenge it was eliminated and the procedure was repeated until all challenges were exhausted. Six iterations (see Annexure-II) were performed and resulted in the ISM based challenge model for blockchain adoption in the Indian public sector perspective and the importance levels are shown in Table VII. 
Table VII.

Final levels for the key challenges of blockchain adoption

\begin{tabular}{|c|c|}
\hline Level\# & Key challenges of blockchain adoption in the public sector \\
\hline $1^{\text {st }}$ & - Adoption of blockchain in the public sector (C16) \\
\hline $2^{\text {nd }}$ & $\begin{array}{l}\text { - Integration with legacy system (C7) } \\
\text { - Reluctance to use blockchain technology (C12) }\end{array}$ \\
\hline $3^{\text {rd }}$ & $\begin{array}{l}\text { - Lack of adequate skills (C5) } \\
\text { - Lack of understanding and knowledge (C11) } \\
\text { - Flexibility (C15) }\end{array}$ \\
\hline $4^{\text {th }}$ & $\begin{array}{l}\text { - Regulatory compliance (C4) } \\
\text { - Legal issues (C8) } \\
\text { - Ethical issues (C13) } \\
\end{array}$ \\
\hline $5^{\text {th }}$ & $\begin{array}{l}\text { - } \text { Scalability (C1) } \\
\text { - } \text { Privacy (C2) } \\
\text { - } \text { Security (C3) } \\
\text { - } \text { Initial cost (C6) } \\
\text { - } \text { Latency cost (C14) }\end{array}$ \\
\hline $6^{\text {th }}$ & $\begin{array}{l}\text { - Lack of standards (C9) } \\
\text { - Lack of validation (C10) }\end{array}$ \\
\hline
\end{tabular}

\subsection{MICMAC analysis}

The MICMAC analysis determines driving and dependence power. To compute these values, the FRM was analysed and the summation of FRM rows and columns were calculated and presented in Table V. The plot is presented in Figure 2. MICMAC structural analysis creates challenge sets (autonomous, dependent, linkage and driver) and this has practical utility as a rich source of information and in-depth insight of the sources and consequences of key challenges of blockchain adoption in the public sector of India. The four sets consist of:

1. Autonomous set: The set of low driving and dependence power (lower left quadrant) items, which have a very weak system impact. No such challenges were identified.

2. Dependent set: This set of challenges has low driving power and high dependence power (lower right quadrant) and has higher importance in the model. Six challenges were detected including: 'Adoption of blockchain in the public sector (C16)', 'Integration with legacy system (C7)', 'Reluctance to use blockchain technology (C12)', 'Lack of adequate skills (C5)' 'Lack of understanding and knowledge $(\mathrm{C} 11)$ ' and 'Flexibility (C15)'. These challenges are significant due to their strong dependence on others and practitioners must nurture the other challenges to achieve these output challenges and enable greater improvement success. 


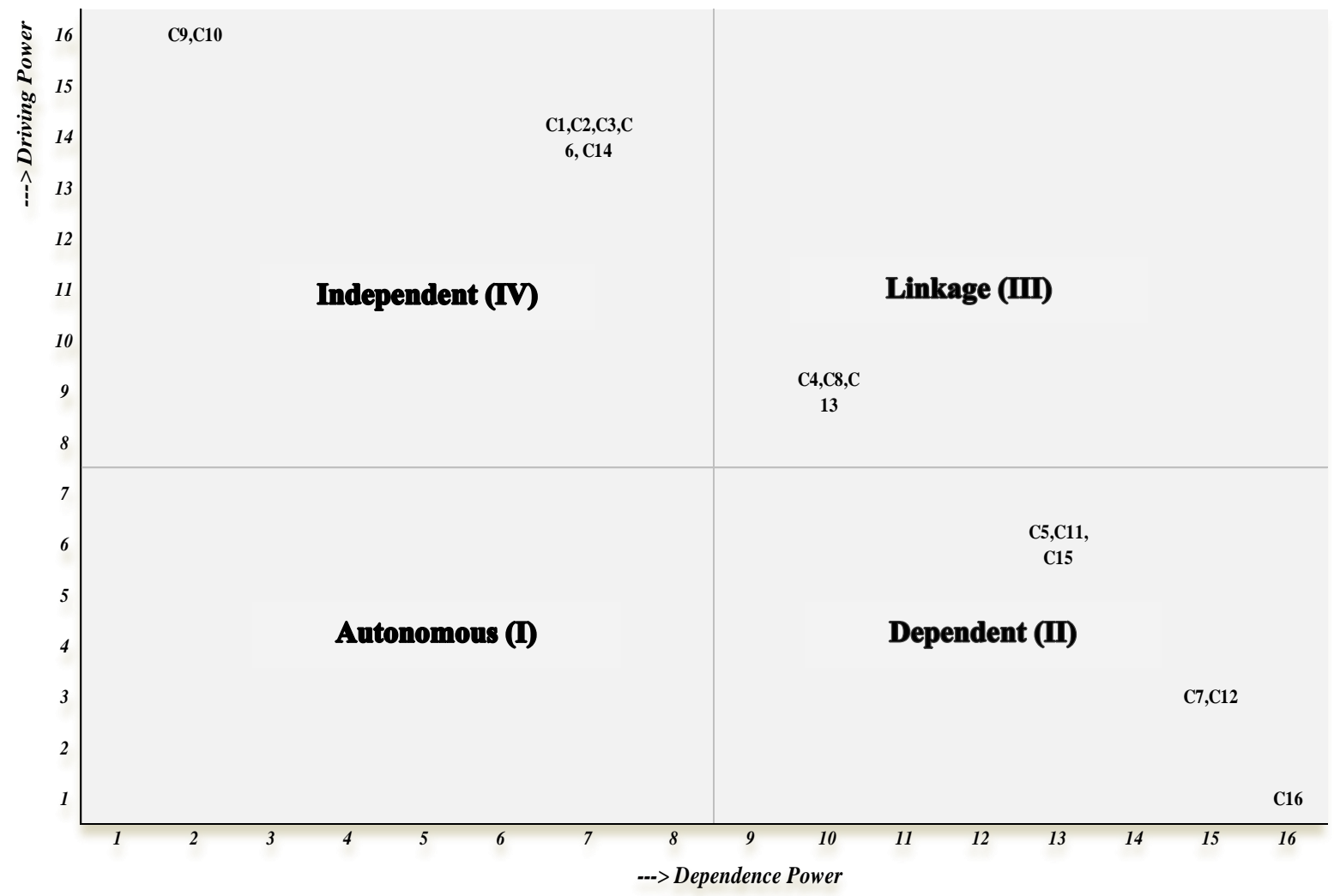

Figure 2. MICMAC analysis

3. Linkage set: This set offers high driving and dependence power (upper right quadrant). It has comparatively lower levels of importance in ISM hierarchical models and the following challenges were detected under this category: 'Regulatory compliance (C4)', 'Legal issues (C8)' and 'Ethical issues (C13)'. These challenges are less stable in nature and practitioners should continuously monitor these types at each stage.

4. Independent set: This set offers high driving power and low dependence power (upper left quadrant) and are the foundations of successful improvement. The challenges include: 'Scalability (C1)', 'Privacy (C2)', 'Security (C3)', 'Initial cost (C6)', 'Latency cost (C14)', 'Lack of standards (C9)' and 'Lack of validation (C10)'. Practitioners must focus on these driving/key challenges on the top priority to ensure they have their minimal effect on the other challenges.

\subsection{Development of ISM based model}

Following the MICMAC analysis, the FRM was used to structure the ISM model (using nodes/vertices and lines of edges), which is known as a digraph in Figure 3. The digraph forms the basis of the ISM model as the transitivity links are removed and assigned to nodes. The model shows the challenges at all different levels and their relationships to the challenges at the same level and a level above it. The levels shown in Figure 3 are also linked with four 
quadrants of the MICMAC diagram where the key driving challenges are all listed in the independent quadrant of the MICMAC diagram. These challenges are high in their driving power and trigger other challenges within the model. None of the challenges were found to be of low driving and low dependence power. This clearly indicates that the challenges are not disjointed in nature. The second quadrant presents the dependent challenges. These challenges exhibit low driving but high dependence power and are therefore, influenced by interdependent factors that have higher levels of driving power. The third quadrant shows all the variables with high dependence and high driving power. These variables largely fall between the top and the bottom layers of variables in the ISM model. They essentially act as the mediating variables between the core driving and dependent variables. The fourth and final quadrant includes all challenges with high driving and low dependence power. These challenges largely fall down the bottom part of the ISM model and trigger other challenges in the proposed ISM model (see Figure 3).

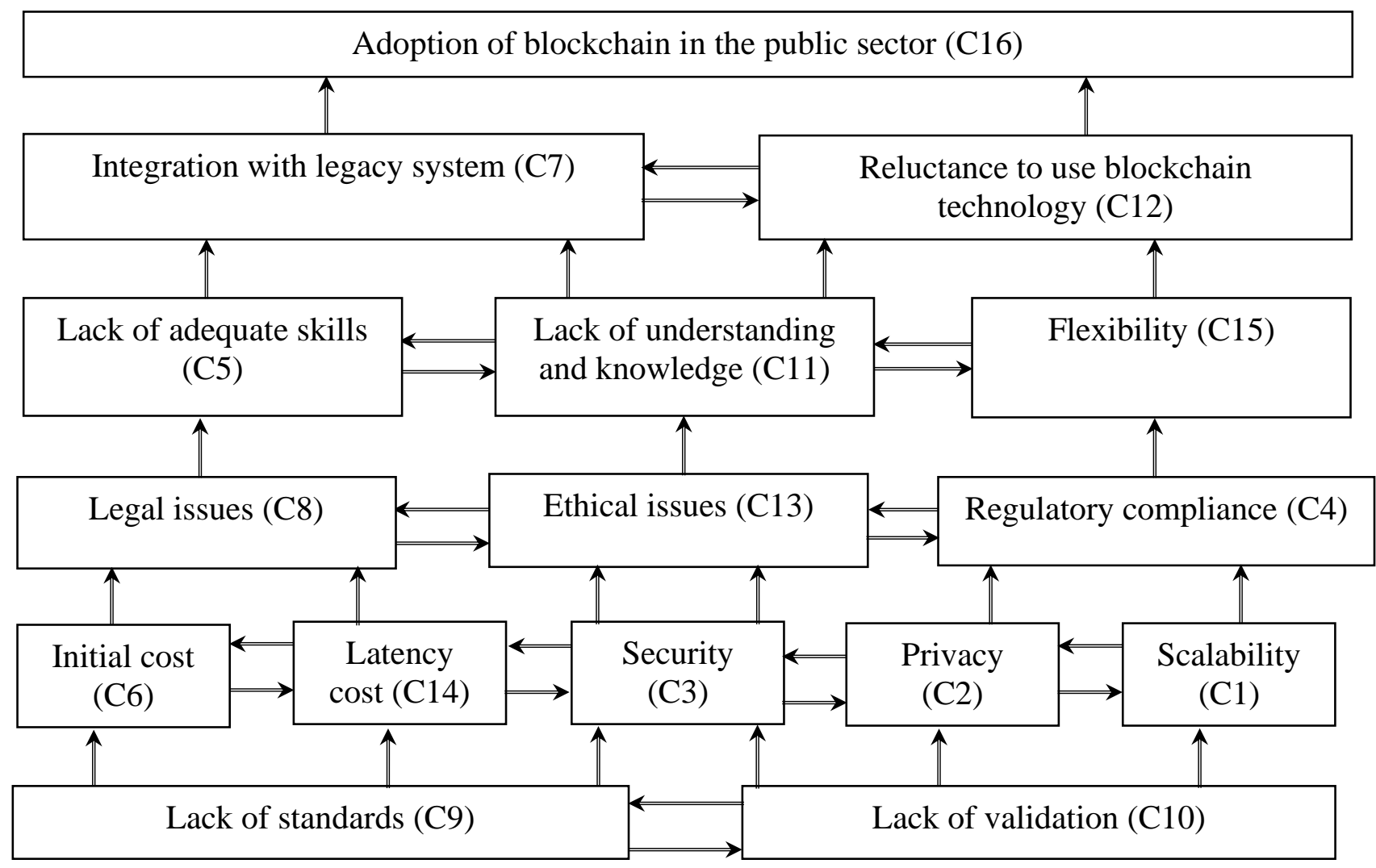

Figure 3. ISM based model

\section{Discussion and analysis of ISM based model}

The ISM model presented in Figure 3 shows that 'Lack of standards (C9)' and 'Lack of validation (C10)' trigger other challenges for the adoption of blockchain in the public sector. This clearly indicates that lack of validation i.e. successfully testing and implementing the 
pilots of blockchain, can impact the way it is adopted and used by the public sector. Likewise, the lack of unified standards in its terminology and perceptions, security risks and vulnerabilities, identity, reference design, classification and legal contracts of this technology impedes it to be fully implemented and adopted by public sector organisations in India. AlSaqaf and Seidler (2017) supported lack of standards or interoperability as a key challenge to the blockchain implementation. Lacity (2018) also found lack of standard as one of the management related challenges of the successful implementation of blockchain in the public sector.

The public sector entities should endeavour to maintain the unified standard of the technology and minimise the risk of its implementation to reap the maximum benefit. The interoperability of blockchain technology should also be established with the existing systems to ensure the seamless functioning of the traditional systems while blockchain is being integrated in the public sector. The government should also validate the implementation of blockchain at the smaller level and if they work well then the technology should be further expanded and disseminated at the wider level. These two challenges further lead to 'Initial cost (C6)', 'Latency cost (C14)', 'Security (C3)', 'Privacy (C2)' and 'Scalability (C1)'.

These hierarchical relationships make a perfect sense as lack of standard and validation could lead to higher initial cost of blockchain implementation, its latency cost and scalability due to new additions of blocks in the current framework, and higher security and privacy given its availability on the public database and vulnerabilities. Although blockchain technology offers a low cost and high security way of sending payments over the network, the lack of standard and validation can make these relationships act reversibly.

The public sector organisations should ensure improved standard and validation of the increasing blocks in the existing blockchain infrastructure to optimise the cost, security and privacy and scalability of its effective implementation. The challenges relating to initial and latency cost have been faced by Estonia, UAE, Singapore and various other countries but they have invested in blockchain technology in the recent past. For example, the USA has invested $\$ 28$ billion for implementing blockchain technology in electronic health records to revive healthcare industry (Makridakis and Christodoulou, 2019).

The challenges (i.e. initial cost, latency cost, security, privacy and scalability) of blockchain implementation illustrated at Level 5 lead to challenges at the next upper level including 'Legal issues (C8)', 'Ethical issues (C13)' and 'Regulatory compliance (C4)'. The mutual links of legal issues, ethical issues and regulatory compliance indicate that all these legal, ethical and regulatory compliance are closely linked to each other as far as implementation of blockchain 
technology is concerned. The practitioners and policymakers should be aware of all legal and ethical issues and regulatory compliance to ensure that blockchain is properly adopted in the public sector without breaching any such compliance. The lack of clarity on regulatory norms has also been highlighted as the key concern among the early adopters of the blockchain in the Indian public sector organisations and hence the government would need to define the framework relating to the nature of transactions on blockchain, policies for recourse, validity for assets and smart contracts used etc. (Deloitte, 2018).

As the challenges related to regulation and ethical and regulatory compliance are both of high driving and high dependence power hence the public sector entities should give elevated priority to resolve these challenges to ensure the hassle free adoption of blockchain. Moreover, given the challenges of higher driving power can easily influence other challenges, the government should prioritise to optimise and address them to ensure that blockchain technology is adopted within the public sector organisations (Janssen et al., 2019).

Further, the challenges related to ethical issues, legal issues and lack of regulatory compliance lead to other three challenges at the next level including 'Lack of adequate skills (C5)', 'Lack of understanding (C11)' and 'Knowledge and flexibility (C15)'. These challenges indicate the importance of human characteristics (such as individual skills and understanding) and systems (i.e. immutable but adaptive nature of technology). The government should ensure that public sector employees get enough training and understanding of the technology being implemented and used in their organisations. The ethical and legal issues and regulatory compliance of the blockchain technology should also be offering flexibility to append its immutable nature to append additional transaction as append only.

The three challenges further lead to 'Integration with the legacy systems (C7)' and 'Reluctance to use blockchain technology (C12)'. These challenges again make a lot of sense as lack of adequate skills, understanding and knowledge of the public sector employees about blockchain technology can make its integration with legacy system difficult and also result in their reluctance to use such technology. Moreover, the dynamic nature of the blockchain technology also makes it difficult to integrate with the legacy system. The public sector organisations should ensure more awareness and skill enhancement training programmes for their employees to embrace this emerging technology. Finally, the lack of integration of blockchain technology and the high levels of resistance amongst public sector employees, eventually affects the adoption of this technology within the Indian public sector. Management need to develop mitigation strategies and policies to break down resistance from staff to ensure the successful deployment of ultra-modern, transparent, secure and speedy systems that that can solve 
increasingly complex problems within India. The government needs to migrate at a steady and structured pace toward blockchain technology if they want to serve their citizens in a better and safer way where transactions are decentralised, publicly visible and robust enough to be breached by hackers.

While many developed countries face the difficulty to integrate blockchain technology with their legacy infrastructure, this is not the case for many other developing and underdeveloped countries as they do not have an established infrastructure and hence it is much easier to integrate this technology for existing systems (Sandner, 2017). India has a distinct strategy where the government has taken the lead in creating public infrastructure and allowed the public as well as private sector innovations to leverage for further development. India has successfully created the basic digital infrastructure such as the largest identity database with some 1.2 billion bibliometric identities called Aadhar, world's most sophisticated digital payment system called unified payments interface with 1.3 billion transactions processed in December 2019, goods and services tax network with more than 400 million returns filed and more than 800 million invoices uploaded, world's largest healthcare initiatives with 500 million beneficiaries covered (NITI Aayog, 2020). All these massive digital infrastructural developments have laid a strong foundation for the public sector organisations willing to build the blockchain technology based infrastructure on the top of these developments.

\subsection{Theoretical contributions}

This study has provided a number of theoretical contributions. Firstly, this is the first study of its type that has collated different set of challenges for the adoption of blockchain in the public sector organisations along with reviewing related literature in this field. Secondly, none of the existing research in the area of blockchain has developed a generic framework of the challenges for its adoption. This study is a step forward to establish links between the discrete challenges using the ISM-MICMAC approach. The proposed framework provides us with various invaluable information about these challenges and also specify the clear categories for them by which it is easier to understand the category of driving and dependent challenges. Such classification would help researchers understand the driving challenges and the other challenges which are dependent on these drivers. The ISM based model also allows researchers to understand such challenges, which have both driving as well as dependent characteristics in them.

The proposed framework through this research provides better understanding for some of the existing frameworks used in the area of emerging technologies in general and blockchain in particular. For example, Jeremy Swinfen Green explored the ethical issues in emerging 
technology and proposed a simple framework that would help developers meet the expectations of the wider society. The framework was proposed for the development and implementation of artificial intelligence (AI) and contained a number of fundamental principles including fairness, accountability, transparency, security, agility, diligence, autonomy, safety and privacy. The framework indicates while engaging with $\mathrm{AI}$ if the organisations follow these principles their potential for harm from this technology will be reduced significantly (Business Reporter, 2020).

However, it is not clear how these principles could be linked up to each other. However, the proposed framework provides improved clarity on how some of the most frequent challenges faced while using the blockchain could be interrelated to each other including security, privacy as can be seen from the ISM based model (see Figure 3). The proposed framework also extends the various other theories (such as social network theory of privacy (Strahilevitz, 2005), game theory (Manshaei et al., 2013), theory of sustainable privacy (Domingo-Ferrer, 2010)) on security and privacy proposed in the context of cloud services (Arpaci et al., 2015), computer and communication networks (Manshaei et al., 2013), social networks (Adhikari and Panda, 2018) etc. Finally, the further derived model provides more focused and specific understanding on how other factors influence reluctance of the public sector organisations in using blockchain technology.

\subsection{Implications for practice and policy}

The proposed ISM based framework provides a number of implications for the public sector for better implementation and adoption of this technology by the government organisations. The ISM based framework indicates that the lack of standard of the blockchain technology is one of the key challenges that triggers other challenges for the adoption of this fast growing technology. As per the statistics of Deloitte, 10\% of the world's GDP will be built around the blockchain applications by 2025 . However, the unified standard for the adoption of mass blockchain still lacking (Kot, 2018). Hence, setting up the unified common standard for the adoption of blockchain is a priority for the government. Similarly, as the blockchain technology has not been tested enough in pilots, lack of validation of this technology can put the solutions built around it to risk. Therefore, the public sector organisations need to audit approach that leverages it, accommodates improved transaction volume and provide real-time data $(\mathrm{PwC}$, 2019).

An article of research published by Tata Communications in 2018 indicates that $44 \%$ of the organisations in its survey would adopt blockchain but also suffered from the widespread 
problem that emerge from implementing new technology such as blockchain. The problem of scalability is one such bottleneck to blockchain adoption and practical implications (Li, 2019). As blockchain based systems suffer from latency issues, public sector organisations would face a major concerns on synchronising the technology with relatively high performing legacy systems. Public sector organisations should be able to resolve this problem to avoid severe transfer delays and high cost on the blockchain network. The technology should be developed to improve transaction speeds to better synchronise with existing systems to save time and cost. Similarly, security and privacy are very significant aspects of emerging blockchain technology as it exists without any third party, indicating there is no trusted person or organisation in the charge of this system. Therefore, the public sector organisations should ensure better privacy and security mechanism for the successful adoption of this technology.

Public sector organisations should also consider the legal and ethical issues and regulatory compliance of this technology for better adoption. This is signified by the high driving and high dependence power acting as key mediating variables between the absolute driving and dependence variables. Public sector organisations should understand legal issues arising from the use of common blockchain applications such as cryptocurrencies, smart contracts and data storage and should be able to explain how such applications can cause industry disruptions and the roadmap to successful implementation (Fulmer, 2019).

The government should also arrange training programmes to improve the employees' awareness and skills to properly use the blockchain technology into their day-to-day functioning. The employees should be well trained to equip themselves with ongoing advancement in the blockchain technology so that they can deal in with the increasing complexity of this technology while working. This will also help overcome their reluctance to use more advanced technology like blockchain for better work efficiency. The better understanding of functioning of blockchain will also help how it can be effectively integrated with the existing legacy systems to ensure seamless functioning of the unified system. This can happen only when the public sector organisations can better prepare and equip their employees with the advancements of this technology through ongoing training programmes and hands on experience to run the integrated system.

\section{Proposed research model and propositions}

Deriving from the ISM framework, we can choose the selected factors to develop the proposed model for the challenges of blockchain adoption. The support for these factors has been found in some discrete literature in context of blockchain and some other technological contexts such 
as FinTech, artificial intelligence etc. (Al-Saqaf and Seidler, 2017; Tang et al., 2019). From 16 factors that have been used to develop a larger and more generic framework for the blockchain adoption in the public sector in India, we considered to take four factors (i.e. lack of standard, lack of validation, security, privacy) from the driving quadrant of the MICMAC and one from the dependent quadrant (i.e. reluctance to use blockchain technology) to develop a parsimonious model for the use of blockchain in the public sector context.

Based on these five constructs, we also developed six relationships for which the propositions would be developed in a way that future researchers could validate them using the primary data. The entire model is divided into three categories where first two factors (i.e. lack of standard and lack of validation) have been kept in the driving category. The next two factors (i.e. security concerns and privacy issues) represent the mediating factor whereas reluctance to use the blockchain technology has been kept as the final dependent variable.

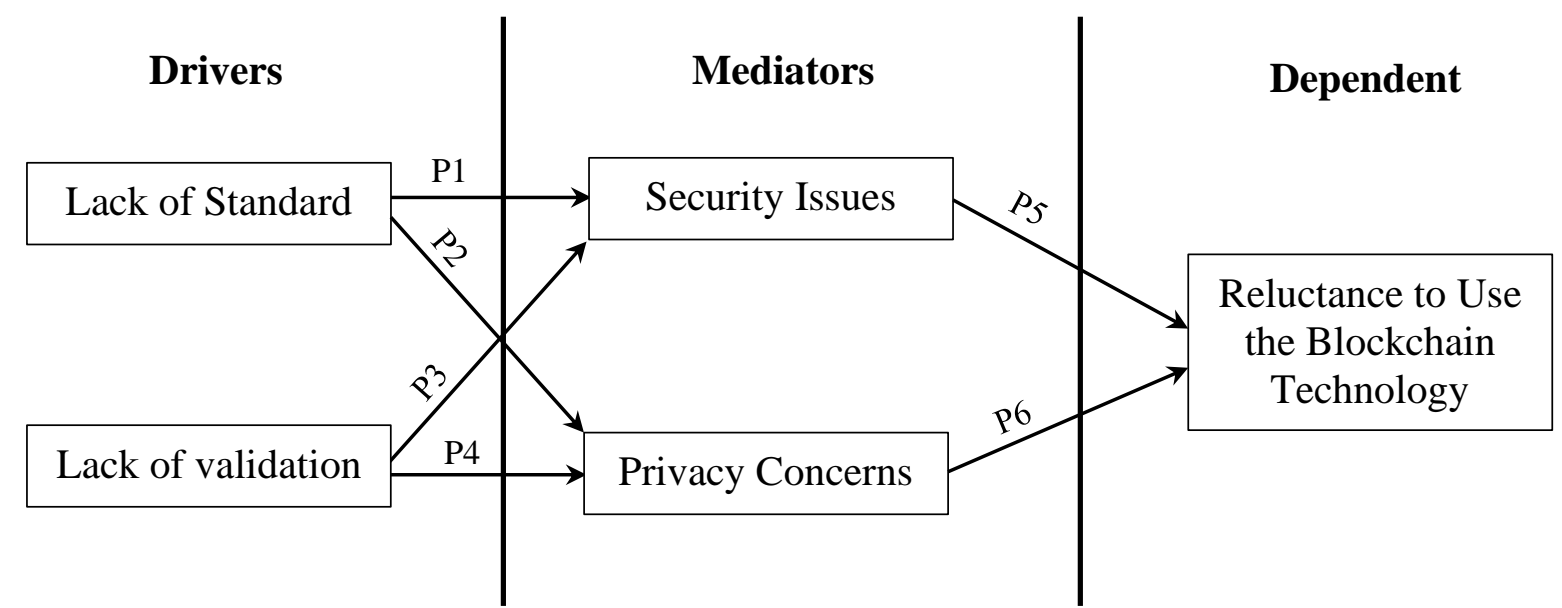

Figure 4. Proposed model for the reluctance to use blockchain technology

\subsection{Lack of standard}

As per Deloitte, $10 \%$ of the global GDP will be built around blockchain applications. However, the unified standard for the blockchain adoption is still lacking. Setting common standard is very critical and a priority for enterprises to overcome some stumbling blocks in the industry such as scalability and interoperability (Kot, 2018). Due to the lack of universal standards, the blockchain space is in the 'state of disarray'. More than 6,500 projects are largely leveraging standalone blockchain platforms and solutions with various protocols allowing different networks to communicate with each other. The lack of such uniformity across blockchain protocols leads to security and privacy concerns, which makes the adoption of this technology almost impossible (De Meijer, 2020). Lack of standard protocols for the blockchain leads to new security risks as different technologies are merged. Forbes report also reaffirmed that lack 
of standard is the reason for one of the fundamental blockchain security issues (Martin, 2018). Based on the above arguments, the following propositions could be formulated:

P1: Lack of standards in the blockchain leads to higher security issues around its use in the public sector organisations.

P2: Lack of standards in the blockchain leads to higher privacy concerns around its use in the public sector organisations.

\subsection{Lack of validation}

The key innovation in the blockchain technology is how the information stored on a distributed ledger is validated by the entire network (Daniel, 2019). A blockchain validator is responsible for verifying transactions within a blockchain and checks if the transactions are legal (Dexter, 2018). There is presently no standard way to validate blockchain-based business processes and lack of knowledge expertise within organisations to standardise this raises questions around various security risks for using this technology (PwC, 2019). With the widespread adoption and lack of validation, user information and data are often mishandled causing a threat to privacy as well (UoC, 2020). Therefore, the following propositions could be formulated from the above discussion:

P3: Lack of validation in the blockchain leads to higher security issues around its use in the public sector organisations.

P4: Lack of validation in the blockchain leads to higher privacy concerns around its use in the public sector organisations.

\subsection{Security issues}

Blockchain technology is fundamentally secure. However, it has exposure to its own security issues that if not accounted for could be detrimental for any businesses. $51 \%$ attack is one of the most widely known blockchain security issues. In this attack, one or more malicious entities gain most of the control of the blockchain's hash rate. Hash rate is a measure of the power of the computers associated to the bitcoin network, which establishes to produce new coins. Various well-known cryptocurrencies such as ZenCash, Verge etc. were the victims of such attacks where attackers walked away with \$20 million due to blockchain security issue in 2018 . An overall massive loss of $\$ 900$ million was witnessed this year due to the blockchain security issues (Lifars, 2019). Such security issues would lead to reluctance among the public sector organisations to use the blockchain technology. Therefore, the following proposition can be formulated:

P5: Security issues linked to blockchain technology leads to its reluctance to use by the public sector organisations. 


\subsection{Privacy concerns}

Blockchain technology has some essential privacy concerns linked to its design. As blockchain is public, each transaction recorded using this technology is available for everyone in the public domain to look at. However, this wouldn't necessarily mean that someone could be notified with their transactions over the network (Price, 2020). As per tech research firm Gartner "blockchain privacy poisoning" (i.e. insertion of personal data into a public blockchain, which makes the blockchain non-complaint under the European General Data Protection Regulation (GDPR) is one of the largest risks being faced by the organisations over the next few years. They further go on to predict that all public blockchains will suffer one or the other form of privacy poisoning by 2022 (CPO Magazine, 2019). Realising the above discussion, we can formulate the following proposition:

P6: Privacy concerns linked to blockchain technology leads to its reluctance to use by the public sector organisations.

\section{Conclusion, Limitations and Future Research Directions}

The paper identified the distinguished set of challenges for the adoption of blockchain technology in the public sector organisations in India. We identified 16 such challenges from the literature and used ISM-MICMAC based methodology to establish interrelationships between them and position them in a specific quadrant as per their driving and dependence power. The findings indicated that challenges such as 'Lack of standards (C9)' and 'Lack of validation (C10)' are the key driving challenges for the adoption of blockchain in the public sector in India. Likewise, 'Integration with the legacy systems (C7)' and 'Reluctance to use blockchain technology (C12)' are largely challenges that are dependent in nature. This paper has been the first of its type that has taken initiative to provide interdependencies between various challenges identified through the literature. The findings emerging from the ISM and MICMAC approach provide a valuable understanding of the hierarchies of challenges and their driving and dependence power. This also helps public sector organisations to understand how they should act to minimise these obstacles to ensure the seamless adoption of this technology in their way of working and what all resources and skills needed to overcome the issues to fully assimilate the adoption of this technology within public sector organisations at large. The generic ISM based framework enabled the development of a parsimonious research model and aided the formulation of propositions between selected variables.

This research has some limitations that should be considered by future researchers. First, this research has used ISM to establish the interrelationships between the identified challenges, as 
such the model not been empirically validated in this study. The future researchers could collect primary data and develop and validate a parsimonious model extracting from the generic framework established using ISM. Future research can also further extend the ISM to Total ISM (i.e. TISM) to estimate key challenges with reference to performance outcomes. Second, the proposed framework does not provide any further guidance on the set of challenges in terms of cause and effect variables. Future researchers could use DEMATEL approach to classify variables into two broader categories. Future researchers can also opt to rank these challenges with regard to their significance as far as the adoption of blockchain technology is concerned. This can be achieved using techniques such as AHP, ANP, TOPSIS etc. to rank the selected variables. Data were collected from experts from the health and education sectors as well as, academia. Therefore, the findings of this research should be considered limited due to this potentially narrow viewpoint, highlighting that future research should consider experts from some other public sector organisations such as Oil and Natural Gas Corporation Limited (ONGC), Indian Oil Corporation (IOC), Steel Authority of India Limited (SAIL), Bharat Heavy Electricals Limited (BHEL), National Thermal Power Corporation (NTPC), Power Grid etc. as well for the better generalisability of the findings (Dennehy and Conboy, 2019). Finally, the research has also formulated a more focused model from the generic framework and formulated propositions between selected variables. However, this model has not been validated by the current research. The future researchers could operationalise the constructs involved in the proposed model and test the authenticity of the proposed model.

\section{References}

Adhikari, K. and Panda, R. K. (2018), "Users' information privacy concerns and privacy protection behaviors in social networks", Journal of Global Marketing, Vol. 31 No. 2, pp. 96-110.

Agarwal, A., Shankar, R., and Tiwari, M. K. (2007), "Modeling agility of supply chain", Industrial Marketing Management, Vol. 36, No. 4, pp. 443-457.

Agi, M. A. and Nishant, R. (2017), "Understanding influential factors on implementing green supply chain management practices: An interpretive structural modelling analysis”, Journal of Environmental Management, Vol. 188, pp. 351-363.

Ahaskar, A. (2019), “90\% enterprise blockchain platform implementations will become obsolete by 2021: Gartner", Accessed from https://bit.ly/2JCLXkV on 25th December 2020.

Al-Saqaf, W., and Seidler, N. (2017), "Blockchain technology for social impact: opportunities and challenges ahead”, Journal of Cyber Policy, Vol. 2, No. 3, pp. 338-354.

Ali, O., Ally, M., and Dwivedi, Y.K. (2020), "The state of play of blockchain technology in the financial services sector: A systematic literature review", International Journal of Information Management, Vol. 54, 102199. 
Alketbi, A., Nasir, Q. and Talib, M. A. (2018), "Blockchain for government services-Use cases, security benefits and challenges", 15th Learning and Technology Conference, pp. 112-119.

Anthes, G. (2015), "Estonia. A model for e-government", Communications of the ACM, Vol. 58 No. 6, pp. 18-20.

Arpaci, I., Kilicer, K. and Bardakci, S. (2015), "Effects of security and privacy concerns on educational use of cloud services", Computers in Human Behavior, Vol. 45, pp. 93-98.

Atlam, H. F., Alenezi, A., Alassafi, M. O. and Wills, G. (2018), "Blockchain with internet of things: Benefits, challenges, and future directions", International Journal of Intelligent Systems and Applications, Vol. 10 No. 6, pp. 40-48.

Attri, R., Dev, N. and Sharma, V. (2013), "Interpretive structural modelling (ISM) approach: An overview", Research Journal of Management Sciences, Vol. 2, No. 2, pp. 3-8.

Axios (2018). Corporate America's blockchain and bitcoin fever is over. (Accessed May 2020) https://www.axios.com/corporate-america-blockchain-bitcoin-fervor-overfb13bc5c-81fd4c12-8a7b-07ad107817ca.html.

Bailis, P., Narayanan, A., Miller, A. and Han, S. (2017), "Research for practice: cryptocurrencies, blockchains, and smart contracts; hardware for deep learning", Communications of the ACM, Vol. 60 No. 5, pp. 48-51.

BDO (2020). Blockchain in the public sector. Accessed from https://bit.ly/3o7CJff on 25th December 2020.

Biswas, B. and Gupta, R. (2019), “Analysis of barriers to implement blockchain in industry and service sectors", Computers \& Industrial Engineering, Vol. 136, pp. 225-241.

Boulos, M. N. K., Wilson, J. T. and Clauson, K. A. (2018), "Geospatial Blockchain: Promises, Challenges, and Scenarios in Health and Healthcare”, BioMed Central, pp. 17-25.

Business Reporter (2020). An ethical framework for emerging technologies. Business Reported, Accessed from https://bit.ly/2LaH03g on $29^{\text {th }}$ December 2020.

Consensys (2020), "Blockchain in the government and the public sector", Accessed from https://bit.ly/3n7omGG on $30^{\text {th }}$ December 2020.

Crosby, M., Nachiappan, Pattanayak, P., Verma, S. and Kalyanaraman, V. (2016), "Blockchain technology: Beyond Bitcoin", Applied Innovation Review, Vol. 2, pp. 6-19.

Daniel (2019). How do blockchain networks validate data? ICO: Retrieved from https://www.ico.li/blockchain-validate-data/ on $1^{\text {st }}$ June 2020.

De Meijer, C.R.W. (2020), "Remaining challenges of blockchain adoption and possible solutions", Finextra: https://bit.ly/36R9cPo on 2nd June 2020.

Deloitte (2018), "Blockchain in Public Sector", Accessed from https://www2.deloitte.com/ content/dam/Deloitte/in/Documents/public-sector/in-ps-blockchain-noexp.pdf $\quad$ on $30^{\text {th }}$ December 2020.

Dennehy, D., and Conboy, K. (2019), "Breaking the flow: a study of contradictions in information systems development (ISD)", Information Technology \& People, DoI: 10.1108/ITP-02-2018-0102

Dexter, S. (2018). How Are Blockchain Transactions Validated? Consensus VS Validation. Mango Research: Retrieved from https://www.mangoresearch.co/blockchain-consensus-vsvalidation/ on $1^{\text {st }}$ June 2020.

Dierksmeier, C. and Seele, P. (2018), "Cryptocurrencies and business ethics", Journal of Business Ethics, Vol. 152, No. 1, pp. 1-14. 
Domingo-Ferrer, J. (2010), "Coprivacy: towards a theory of sustainable privacy", International Conference on Privacy in Statistical Databases (pp. 258-268). Springer, Berlin, Heidelberg.

Dorri, A., Kanhere, S. S., and Jurdak, R. (2017), "Towards an optimized blockchain for IoT", In 2017 IEEE/ACM Second International Conference on Internet-of-Things Design and Implementation, pp. 173-178.

Dou, Y., Zhu, Q. and Sarkis, J. (2014), "Evaluating green supplier development programs with a grey-analytical network process-based methodology", European Journal of Operational Research, Vol. 233 No. 2, pp. 420-431.

Dubey, R. and Ali, S. S. (2014), "Identification of flexible manufacturing system dimensions and their interrelationship using total interpretive structural modelling and fuzzy MICMAC analysis", Global Journal of Flexible Systems Management, Vol. 15 No. 2, pp. 131-143.

Dubey, R., Gunasekaran, A., Bryde, D. J., Dwivedi, Y. K., and Papadopoulos, T. (2020), "Blockchain technology for enhancing swift-trust, collaboration and resilience within a humanitarian supply chain setting”, International Journal of Production Research, 118. DoI: https://doi.org/10.1080/00207543.2020.1722860.

Dubey, R., Gunasekaran, A., Papadopoulos, T., Childe, S. J., Shibin, K. T. and Wamba, S. F. (2017), "Sustainable supply chain management: framework and further research directions", Journal of Cleaner Production, Vol. 142, pp. 1119-1130.

Fridgen, G., Lockl, J., Radszuwill, S., Rieger, A., Schweizer, A., and Urbach, N. (2018), “A solution in search of a problem: A method for the development of blockchain use cases", AMCIS 2018, Texas, USA.

Fulmer, N. (2019), "Exploring the legal issues of blockchain applications", Akron Law Review, Vol. 52 No. 1, pp. 162-192.

Gartner (2019), "Gartner Predicts 90\% of Current Enterprise Blockchain Platform Implementations Will Require Replacement by 2021", Gartner Press Release, Accessed from https://www.gartner.com/en/newsroom/press-releases/2019-07-03-gartner-predicts90--of-current-enterprise-blockchain.

Gomber, P., Kauffman, R. J., Parker, C. and Weber, B. W. (2018), “On the fintech revolution: Interpreting the forces of innovation, disruption, and transformation in financial services", Journal of Management Information Systems, Vol. 35 No. 1, pp. 220-265.

Haleem, A., Luthra, S., Mannan, B., Khurana, S., Kumar, S. and Ahmad, S. (2016), "Critical factors for the successful usage of fly ash in roads \& bridges and embankments: Analyzing Indian perspective", Resources Policy, Vol. 49, pp. 334-348.

Hughes, L., Dwivedi, Y.K., Misra, S., Rana, N.P., Raghavan, V. and Akella, V. (2019), "Blockchain Research, Practice and Policy: Applications, Benefits, Limitations, Emerging Research Themes and Research Agenda", International Journal of Information Management, Vol. 49, pp. 114-129.

Jakhar, S. K. and Barua, M. K. (2014), “An integrated model of supply chain performance evaluation and decision-making using structural equation modelling and fuzzy AHP”, Production Planning \& Control, Vol. 25 No. 11, pp. 938-957.

Janssen, M., Luthra, S., Mangla, S., Rana, N. P., and Dwivedi, Y. K. (2019), "Challenges for adopting and implementing IoT in smart cities”, Internet Research, Vol. 29 No. 6, pp. 15891616. 
Kamble, S., Gunasekaran, A. and Arha, H. (2019), "Understanding the Blockchain technology adoption in supply chains-Indian context", International Journal of Production Research, Vol. 57 No. 7, pp. 2009-2033.

Karamchandani, A., Srivastava, S. K. and Srivastava, R. K. (2020), "Perception-based model for analyzing the impact of enterprise blockchain adoption on SCM in the Indian service industry", International Journal of Information Management, Vol. 52, pp. 102019.

Killmeyer, J., White, M. and Chew, B. (2017), “Will blockchain transform the public sector?”, Deloitte University Press, Accessed from: https://bit.ly/3pDRreB on 30th December 2020.

Kot, I. (2018), "Lack of standards in blockchain technology: What to do? iTransition", Accessed from https://www.itransition.com/blog/lack-of-standards-in-blockchaintechnology-what-to-do on $8^{\text {th }}$ November 2019.

Lacity, M. C. (2018), “Addressing key challenges to making enterprise blockchain applications a reality", MIS Quarterly Executive, Vol. 17 No. 3, pp. 201-222.

Li, K. (2019), "The blockchain scalability problem and the race for Visa-like transaction speed", Hackernoon, Accessed from https://bit.ly/2AtUpxU on $9^{\text {th }}$ November 2019.

Lifars (2019), “Top 5 blockchain security issues in 2019”, Link: https://bit.ly/3eKhhYU on 2nd June 2020.

Lindsey, N. (2019), "Blockchain privacy poisoning a new concern in Post GDPR Era", CPO Magazine, Retrieved from: https://www.cpomagazine.com/data-protection/blockchainprivacy-poisoning-a-new-concern-in-post-gdpr-era/ on $2^{\text {nd }}$ June 2020.

Luthra, S., Govindan, K., Kannan, D., Mangla, S. K. and Garg, C. P. (2017), “An integrated framework for sustainable supplier selection and evaluation in supply chains", Journal of Cleaner Production, Vol. 140, pp. 1686-1698.

Mahmoudi, A., Mi, X., Liao, H., Feylizadeh, M. R. and Turskis, Z. (2020), "Grey best-worst method for multiple experts multiple criteria decision making under uncertainty", Informatica, Vol. 31 No. 2, pp. 331-357.

Makridakis, S., and Christodoulou, K. (2019), "Blockchain: Current Challenges and Future Prospects/Applications", Future Internet, Vol. 11 No. 258, pp. 1-16.

Mangla, S. K., Luthra, S., Mishra, N., Singh, A., Rana, N. P., Dora, M. and Dwivedi, Y. (2018), "Barriers to effective circular supply chain management in a developing country context", Production Planning \& Control, Vol. 29 No. 6, pp. 551-569.

Manikandan, A. (2019), "ICICI, Kotak, Axis among 11 to launch blockchain-linked funding for SMEs", Accessed from https://bit.ly/2U5W97z on 24th May 2020.

Manshaei, M. H., Zhu, Q., Alpcan, T., Bacşar, T. and Hubaux, J. P. (2013), "Game theory meets network security and privacy”, ACM Computing Surveys, Vol. 45 No. 3, pp. 1-39.

Martin, R. (2018), "5 blockchain security risks and how to reduce them Ignite", Retrieved from https://igniteoutsourcing.com/blockchain/blockchain-security-vulnerabilities-risks/ on $31^{\text {st }}$ May 2020.

Mathivathanan, D., Mathiyazhagan, K., Rana, N.P., Khorana, S. and Dwivedi, Y.K. (2021), "Analysing barriers in the adoption of blockchain technology in supply chain: A Total Interpretive Structural Modelling (TISM) approach", International Journal of Production Research. 
Mathiyazhagan, K., Govindan, K., NoorulHaq, A. and Geng, Y. (2013), “An ISM approach for the barrier analysis in implementing green supply chain management", Journal of Cleaner Production, Vol. 47, pp. 283-297.

Mendling, J., Weber, I., Aalst, W. V. D., Brocke, J. V., Cabanillas, C., Daniel, F., ... and Gal, A. (2018), "Blockchains for business process management-challenges and opportunities”, ACM Transactions on Management Information Systems, Vol. 9 No. 1, pp. $1-16$.

Mi, X., Tang, M., Liao, H., Shen, W. and Lev, B. (2019), "The state-of-the-art survey on integrations and applications of the best worst method in decision making: Why, what, what for and what's next?”, Omega, Vol. 87, pp. 205-225.

NITI Aayog (2020), "Blockchain: The India Strategy", Draft Discussion Paper, Accessed from https://bit.ly/3hAyrdX on 29th December 2020.

Olnes, S., Ubacht, J. and Janssen, M. (2017), "Blockchain in government: Benefits and implications of distributed ledger technology for information sharing", Government Information Quarterly, Vol. 34 No. 3, pp. 355-364.

Önder, I. and Treiblmaier, H. (2018), "Blockchain and tourism: Three research propositions", Annals of Tourism Research, Vol. 72 No. C, pp. 180-182.

Palas, M. J. U. and Bunduchi, R. (2020), "Exploring interpretations of blockchain's value in healthcare: a multi-stakeholder approach", Information Technology \& People, DoI: 10.1108/ITP-01-2019-0008.

Palavesh, S. (2019), “Can blockchain technology help India grow its GDP?”, Entrepreneur India, Accessed from https://www.entrepreneur.com/article/328040 on 30th December 2020.

Price, D. (2020), "5 Blockchain Problems: Security, Privacy, Legal, Regulatory, and Ethical Issues. Blocks decoded", Retrieved from https://bit.ly/2Mtf47P on 2nd June 2020 on $23^{\text {rd }}$ December 2020.

PwC (2018), "Estonia - The Digital Republic Secured by Blockchain. Accessed from PwC document", Accessed from https://pwc.to/2X2Z5CWon 24th May 2020.

PwC (2019), "PwC blockchain validation solution: Innovate with confidence", Accessed from https://pwc.to/3o6pxYk on $20^{\text {th }}$ May 2020.

Queiroz, M. M. and Wamba, S. F. (2019), "Blockchain adoption challenges in supply chain: An empirical investigation of the main drivers in India and the USA", International Journal of Information Management, Vol. 46, pp. 70-82.

Queiroz, M. M., Fosso Wamba, S., De Bourmont, M. and Telles, R. (2020), "Blockchain adoption in operations and supply chain management: Empirical evidence from an emerging economy", International Journal of Production Research, pp. 1-17.

Rana, N. P., Barnard, D. J., Baabdullah, A. M., Rees, D. and Roderick, S. (2019), "Exploring barriers of m-commerce adoption in SMEs in the UK: Developing a framework using ISM", International Journal of Information Management, Vol. 44, pp. 141-153.

Rana, N.P., Luthra, S., and Rao, H.R. (2020), "Key challenges to digital financial services in emerging economies: The Indian context", Information Technology \& People, Vol. 33 No. 1, 198-229. 
Raut, R. D., Narkhede, B. and Gardas, B. B. (2017), "To identify the critical success factors of sustainable supply chain management practices in the context of oil and gas industries: ISM approach", Renewable and Sustainable Energy Reviews, Vol. 68, pp. 33-47.

Reyna, A., Martín, C., Chen, J., Soler, E., and Díaz, M. (2018), "On blockchain and its integration with IoT. Challenges and opportunities", Future Generation Computer Systems, Vol. 88, pp. 173-190.

Sadjadi, S. and Karimi, M. (2018), "Best-worst multi-criteria decision-making method: A robust approach", Decision Science Letters, Vol. 7 No. 4, pp. 323-340.

Sandner, P. (2017), "Blockchain opportunities for social impact in developing countries", Energypedia, Accessed from https://bit.ly/34YB2cE on 29th December 2020.

Saxena, J. P. and Vrat, P. (1990), "Impact of indirect relationships in classification of variables - a MICMAC analysis for energy conservation", Systems Research, Vol. 7 No. 4 , pp. 245-253.

Schuetz, S. and Venkatesh, V. (2020), "Blockchain, adoption, and financial inclusion in India: Research opportunities", International Journal of Information Management, Vol. 52, pp. 101936.

Sheng-Li, S., Xiao-Yue, Y., Hu-Chen, L. and Zhang, P. (2018), "DEMATEL Technique: A Systematic Review of the State-of-the-Art Literature on Methodologies and Applications", Mathematical Problems in Engineering, Vol. 2018, pp. 1-33.

Shibin, K. T., Gunasekaran, A. and Dubey, R. (2017), "Explaining sustainable supply chain performance using a total interpretive structural modeling approach", Sustainable Production and Consumption, Vol. 12, pp. 104-118.

Sindhwani, R. and Malhotra, V. (2017), "Modelling and analysis of agile manufacturing system by ISM and MICMAC analysis", International Journal of System Assurance Engineering and Management, Vol. 8 No. 2, pp. 253-263.

Song, W., Zhu, Y. and Zhao, Q. (2020), “Analyzing barriers for adopting sustainable online consumption: A rough hierarchical DEMATEL method", Computers \& Industrial Engineering, Vol. 140, pp. 106279.

Strahilevitz, L. J. (2005), “A social networks theory of privacy”, The University of Chicago Law Review, pp. 919-988.

Sushil (2018), "How to check correctness of total interpretive structural models?", Annals of Operations Research, Vol. 270 No. 1-2, pp. 473-487.

Tang, H., Shi, Y. and Dong, P. (2019), "Public blockchain evaluation using entropy and TOPSIS”, Expert Systems with Applications, Vol. 117, pp. 204-210.

Tang, Y., Xiong, J., Becerril-Arreola, R., and Iyer, L. (2019), "Ethics of blockchain: A framework of technology, applications, impacts, and research directions", Information Technology \& People. DoI: 10.1108/ITP-10-2018-0491.

Tasca, P., and Tessone, C. J. (2017), "Taxonomy of blockchain technologies: Principles of identification and classification", arXiv preprint arXiv:1708.04872.

Thakur, V., Doja, M. N., Dwivedi, Y. K., Ahmad, T., and Khadanga, G. (2020), "Land records on blockchain for implementation of land titling in India", International Journal of Information Management, Vol. 52, 101940.

UoC (2020), "Blockchain's roles in strengthening cybersecurity and protecting privacy", University of California Berkeley Library. 
Wagner, S. M. and Neshat, N. (2010), "Assessing the vulnerability of supply chains using graph theory", International Journal of Production Economics, Vol. 126 No. 1, pp. 121129.

Wamba, S. F., Queiroz, M. M. and Trinchera, L. (2020), "Dynamics between blockchain adoption determinants and supply chain performance: An empirical investigation", International Journal of Production Economics, pp. 107791.

Wang, J., Wu, P., Wang, X., and Shou, W. (2017), "The outlook of blockchain technology for construction engineering management", Frontiers of Engineering Management, pp. 67-75.

Wang, R., Lin, Z., and Luo, H. (2019), "Blockchain, bank credit and SME financing”, Quality \& Quantity, Vol. 53 No 3, pp. 1127-1140.

Warfield, J. N. (1974), "Toward interpretation of complex structural models", IEEE Transactions on Systems, Man, and Cybernetics, Vol. 5, pp. 405-417.

Weston, R. and Gore Jr, P. A. (2006), "A brief guide to structural equation modeling", The Counseling Psychologist, Vol. 34 No. 5, pp. 719-751.

White, G. R. (2017), "Future applications of blockchain in business and management: A Delphi study", Strategic Change, Vol. 26 No 5, pp. 439-451.

Xiao, L., Pan, T., Mou, J., and Huang, L. (2020), "Understanding determinants of social networking service fatigue: an interpretive structural modeling approach", Information Technology \& People, DoI: 10.1108/ITP-04-2020-0169.

Yadav, V. S., Singh, A. R., Raut, R. D. and Govindarajan, U. H. (2020), "Blockchain technology adoption barriers in the Indian agricultural supply chain: An integrated approach", Resources, Conservation and Recycling, Vol. 161, pp. 104877.

Yli-Huumo, J., Ko, D., Choi, S., Park, S. and Smolander, K. (2016), "Where is current research on blockchain technology? - a systematic review", PloS One, Vol. 11 No 10, pp. e0163477.

Zheng, Z., Xie, S., Dai, H. N., Chen, X. and Wang, H. (2018), "Blockchain challenges and opportunities: A survey”, International Journal of Web and Grid Services, Vol. 14 No. 4, pp. 352-375.

Zheng, Z., Xie, S., Dai, H., Chen, X. and Wang, H. (2017), "An overview of blockchain technology: Architecture, consensus, and future trends", IEEE International Congress on Big Data, pp. 557-564.

\section{Appendix A}

\section{Significance of the challenges for the blockchain adoption in the public sector}

Rate the following challenges for digital financial services in context of India on 5-point Likert scale (1-not significant, 2-somewhat significant, 3-significant, 4-very significant and 5extremely significant) (Please choose only ONE in each row).

\begin{tabular}{|c|l|c|c|c|c|c|}
\hline \multirow{2}{*}{ SN } & \multirow{2}{*}{ Challenge } & \multicolumn{5}{|c|}{ Rating } \\
\hline & & $\mathbf{1}$ & $\mathbf{2}$ & $\mathbf{3}$ & $\mathbf{4}$ & $\mathbf{5}$ \\
\hline 1. & Scalability & & & & & \\
\hline 2. & Privacy & & & & & \\
\hline 3. & Security & & & & & \\
\hline 4. & Regulatory compliance & & & & & \\
\hline 5. & Lack of adequate skills & & & & & \\
\hline 6. & Initial cost & & & & & \\
\hline 7. & Integration with legacy system & & & & & \\
\hline
\end{tabular}




\begin{tabular}{|c|l|c|c|c|c|c|}
\hline 8. & Legal issues & & & & & \\
\hline 9. & Lack of standards & & & & & \\
\hline 10. & Lack of validation & & & & & \\
\hline 11. & Lack of understanding and knowledge & & & & & \\
\hline 12. & Reluctance to use blockchain technology & & & & & \\
\hline 13. & Ethical issues & & & & & \\
\hline 14. & Latency cost & & & & & \\
\hline 15. & Flexibility & & & & & \\
\hline 16. & Adoption of blockchain in the public sector & & & & & \\
\hline
\end{tabular}

Contextual relationships between challenges of blockchain adoption in the public sector After finalizing the key challenges of blockchain adoption, the contextual relationships among them are formed. To represent these contextual relationships, a SSIM matrix is constructed (for which the entries in Table A are to be filled). Following four symbols are used (for filling the entries in Table 1) indicating the direction of interaction between two challenges (say, $i$ and $j$ ). $\mathrm{V}$ - Challenge $\mathrm{i}$ helps achieve or influences challenge $\mathrm{j}$, A - Challenge $\mathrm{j}$ helps achieve or influences challenge $i$,

$\mathrm{X}$ - Challenges $\mathrm{i}$ and $\mathrm{j}$ help achieve or influence each other, and $\mathrm{O}$ - Challenges $\mathrm{i}$ and $\mathrm{j}$ are unrelated

For example [1] if you think that only Variable $\mathrm{i}=1$ i.e. 'Scalability' influences Variable $\mathrm{j}=2$ i.e. 'Privacy' then insert the symbol ' $V$ ' for $i=1$ and $j=2$. [2] If you think that only $j=2$ influences $i=1$ then insert symbol ' $A$ ' for $i=1$ and $j=2$. [3] If you think that both variables $i=1$ and $j=2$ influence each other then update the cell with $i=1$ and $j=2$ with symbol ' $X$ ', or [4] If you think that both variables with $i=1$ and $j=2$ are unrelated to each other then update the cell with $i=1$ and $\mathrm{j}=2$ with symbol ' $\mathrm{O}$ '. Please do this exercise for all the cells indicated in Table 1 . The example cell (with $\mathrm{i}=1$ and $\mathrm{j}=2$ ) is shaded in BLACK below for your understanding.

Table A. Relationship matrix for challenge of blockchain adoption in the public sector

\begin{tabular}{|c|c|c|c|c|c|c|c|c|c|c|c|c|c|c|c|}
\hline Variable $\mathrm{i}$ & 16 & 15 & 14 & 13 & 12 & 11 & 10 & 9 & 8 & 7 & 6 & 5 & 4 & 3 & 2 \\
\hline 1 & & & & & & & & & & & & & & & \\
\hline 2 & & & & & & & & & & & & & & & \\
\hline 3 & & & & & & & & & & & & & & & \\
\hline 4 & & & & & & & & & & & & & & & \\
\hline 5 & & & & & & & & & & & & & & & \\
\hline 6 & & & & & & & & & & & & & & & \\
\hline 7 & & & & & & & & & & & & & & & \\
\hline 8 & & & & & & & & & & & & & & & \\
\hline 9 & & & & & & & & & & & & & & & \\
\hline 10 & & & & & & & & & & & & & & & \\
\hline 11 & & & & & & & & & & & & & & & \\
\hline 12 & & & & & & & & & & & & & & & \\
\hline 13 & & & & & & & & & & & & & & & \\
\hline 14 & & & & & & & & & & & & & & & \\
\hline 15 & & & & & & & & & & & & & & & \\
\hline
\end{tabular}

[1] Scalability, [2] Privacy, [3] Security, [4] Regulatory compliance, [5] Lack of adequate skills, [6] Initial cost, [7] Integration with legacy system, [8] Legal issues, [9] lack of standards, [10] Lack of validation, [11] Lack of understanding and knowledge, [12] Reluctance to use blockchain technology, [13] Ethical issues, [14] Latency cost, [15] Flexibility, [16] Adoption of blockchain in the public sector 